\title{
Full-scale Detached Eddy Simulation of kerosene fueled scramjet combustor based on skeletal mechanism
}

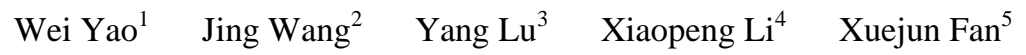 \\ Key Laboratory of High Temperature Gas Dynamics, Institute of Mechanics, CAS, No.15 Beisihuanxi Road, Beijing \\ 100190, P.R. China
}

\begin{abstract}
Large Eddy Simulation (LES) of kerosene fueled scramjet combustor is generally scare in the literature, due mainly to the formidable computational cost arisen by complex kerosene mechanism. In this study, the skeletal reduction of a detailed reaction mechanism (2185 species/8217 steps) of aviation kerosene is conducted using directed relation graph with error propagation and sensitivity analysis (DRGEPSA) method, resulting a skeletal mechanism consisting of 39 species/153 elemental reactions for China Daqing RP-3 aviation kerosene. The comparisons of adiabatic flame temperature, total heat release, ignition delay and laminar flame speed predicted by the skeletal mechanism show an overall good accordance with the original detailed reaction mechanism. Then a three-dimensional Detached Eddy Simulation (DES) modeling based on the skeletal kerosene mechanism is employed for the numerical analysis of a full-scale scramjet combustor, which has been experimentally tested in a long-time direct connect supersonic combustion test platform (abbreviated as DTZ) assembled in Chinese Academy of Sciences (CAS). Pressure and heat flux measurement systems are attached to the combustor assembly to monitor the real-time combustion performance and provide validation data for the numerical modeling. Three cases with fuel equivalence ratios from $0.8,1.0$ to 1.2 and the same crossflow conditions at Mach 2.0 are modeled. The time-averaged static pressure and heat flux are in generally good agreement with the experiment with the peak heat flux slightly underpredicted. The instantaneous and/or time-averaged pressure, momentum, temperature and turbulence fields, which are difficult to be measured, are analyzed to reveal the main flow and combustion physics, especially those related to the flame distribution and holding. The combustion is identified as in ramjet mode for the investigated cases. With the increasing of fuel equivalence ratio, the shock train propagates upstream in the isolator and the interaction between the upstream and downstream combustion assumes different patterns.
\end{abstract}

\section{Introduction}

More than 50 years of efforts in ground and flight tests prove the feasibility of the concept of scramjet for future hypersonic flight [1], while some remaining bottlenecks, such as the mixing and combustion mechanism, need to be eliminated through a physical understanding of the flow and combustion processes in scramjet combustors. Although experimental tests have been extensively conducted, little insight is provided for the transient internal flow and thermal environments due to that the difficulties in measuring the high-speed complex unsteady flowfield restrict the available experimental data. High-resolution numerical modeling, especially those based on large eddy simulation (LES) technique, is of great use for a close examination of the flow physics in scramjet combustors as well as their engineering design [2]. However, due to the prohibitive computational cost and the lack of experimental data, most of the modeling analysis focus primarily on individual scramjet component, e.g. inlet/isolator, supersonic combustor and expander/nozzle, while modeling of the integrated flow path in a full-scale combustion is generally scarce. From the literature, the most preferred modeling cases are the HyperShot I\&II [3-10] and SCHOLAR [11-16], due a large degree to their relative complete data on experimental setup and measurements

\footnotetext{
${ }^{1}$ Associate researcher, Hypersonic Research Center (CAS), P.R. China.

${ }^{2}$ Associate researcher, Hypersonic Research Center (CAS), P.R. China.

${ }^{3}$ Assistant researcher, Hypersonic Research Center (CAS), P.R. China.

${ }^{4}$ PHD student, Hypersonic Research Center (CAS), P.R. China.

${ }^{5}$ Researcher, Hypersonic Research Center (CAS), P.R. China, AIAA member.
} 
for model validation. Simulations based on the experimental cases tested on some other scramjet combustor facilities, such as the DLR scramjet combustor [17, 18], the University of Virginia's Supersonic Combustion Facility (SCF) [18-21] and the CUBRC Combustion Duct [22], are also growing vigorously. To date, promising work on modeling those experimental cases is still under way to validate the physical models and shock/turbulence capturing algorithms for supersonic combustion, as well as to improve the computational efficiency [23-25].

The supersonic combustion in scramjet combustors can be classified as high-Ma (Mach number) wall-bounded reacting flow, where the main flow physics are shock wave/turbulent boundary layer interaction (SWTBLI), shock/shear layer interaction, turbulence/chemistry interaction (TCI) and shock train/combustion interaction etc. A canonical flow encountered in scramjet combustors is the jet in supersonic crossflow (JISC), which is extensively utilized for transverse fuel injection to increase mixing in order to achieve the required heat release schedule with shorter combustor residence times. Some prior work in applying LES to JISCs at different jet-to-crossflow momentum flux ratios and with different fuel molecular weights has been extensively conducted [14, 26-50] based on the experimental cases of Lin et. al. [51, 52], Hannemann et. al. [53], Santiago and VanLerberghe [54-56], Gruber et. al.[57-60], Ben-Yakar [61], Aso et. al. [62], Spaid and Zukoski [63], and Maddalena et. al.[64], etc. to reveal the mixing and combustion mechanisms. And in order to reduce the grid requirement in near-wall regions, wall-modeled LES [15, 33, 37, 65-67] or hybrid RANS (Reynolds-Averaged Navier-Stokes) / LES [14, 16-21, 26, 28-31, 36, 68-70] is usually used. In terms of existing LES techniques, one of the main challenges for supersonic combustion modeling lies in accounting for the effect of Mach number on flame regime in the Borghi diagram [13, 71], which is essentially due to the general lack of physical understanding on the effects of supersonic conditions on turbulence, reaction rates, and flame regimes [25]. Finite-rate-chemistry Direct numerical simulation (DNS) model in conjunction with detailed kinetic mechanism may exactly reveal the TCI modes, but the computational cost is far beyond the affordance of current computer architectures. To properly address the subgrid (SGS) turbulent effects, chemical reactions as well as their complex interaction in supersonic combustion, persistent endeavor in developing and validating the SGS models, kinetic mechanisms and turbulent combustion models is necessary.

Most of those aforementioned LES based supersonic combustion modellings are based on hydrogen, e.g. those based on HyperShot I\&II [3-10] or SCHOLAR cases [11-16], with a few based on pure hydrocarbons (e.g. ethylene $[42,72]$, methane [73, 74] and acetone [75]), however few are based kerosene [76-79]. Kerosene is a more economic and practical fuel for scramjets cruising at Mach number 4-8, which is the short-term goal of hypersonic flight in the next few decades. However, compared with hydrogen fuel, the difficulty in using kerosene as scramjet fuel is that the slower reaction process and lower heating value hinder the improvement of combustion efficiency. Thus there is a more pressure need to gain a physical understanding of the flow and combustion processes in kerosene fueled scramjet combustors by aid of high-fidelity modeling techniques, when non-intrusive experimental diagnostic methods for supersonic combustion are insufficient. One important reason in the scarcity of modeling studies of kerosene fueled supersonic combustion can be attributed to the formidable computational cost arisen by large-scale kerosene mechanisms, which usually involve thousands of species and even more elemental reactions. The mechanisms used in those previous kerosene fueled supersonic combustion modeling [76-79] are all based on simple global or semi-kinetic mechanisms. Kerosene mechanisms developed for computational fluid dynamic (CFD) should meet the requirements of high fidelity of overall kinetic characteristics and high computational efficiency. In fact, even substituting kerosene by simple hydrocarbon species, e.g. purely n-Decane, the corresponding mechanism still contains hundreds or even thousands of elemental reactions and at least hundreds of species. On one hand, the computational cost is generally scaled with the square of species number [80]. On the other hand, the difference in the characteristic times of each elemental reactions will result in large stiffness of the reacting system [80, 81]. Detailed mechanism generally applies only to small-scale flow problems, while a proper species number for supersonic combustion modeling based on LES or DNS is typically around 20-50. Reduced or skeletal kerosene mechanisms specifically developed for supersonic combustion modeling are generally few in published studies. The global or semi-kinetic mechanisms [82-85] fitted based on experimental data apply only to a narrow region of combustion conditions, and the reduction is usually not conducted based on elemental reactions.

The typical combustion conditions in scramjet combustors are in the range of static pressure 0.5-3.0 KPa and static temperature 300-3000 K. Within the condition range, detailed mechanisms are usually reduced by two types of methods: (1) removing the species and elemental reactions having less influence on the physical quantities of interest (e.g. the total heat release, the production rates of main species) with the aid of sensitivity analysis (SA) [86] and Computational Singularity Perturbation (CSP) from the detailed mechanism to obtain a skeletal mechanism, (2) building algebraic relations among species concentrations through Quasi-Steady State Assumption (QSSA) [87, 88] and Partial Equilibrium Assumption (PEA) $[89,90]$ to actually reduce the number of unresolved species. However, the reduction efficiency measured by the mechanism sizes before and after the reduction by SA and CSP is generally low and hence the finial skeletal mechanism is usually still too large for supersonic combustion modeling, while the 
application of QSSA and PEA involves complex matrix solving, which deteriorates the computational efficiency and numerical stability. Recently, Lu et al. [91-93] proposed a novel skeletal reduction method, i.e. directed relation graph with error propagation and sensitivity analysis (DRGEPSA), which has high reduction efficiency and reliability especially for large detailed mechanisms, e.g. the kerosene mechanisms with thousands of species [94, 95]. DRGEPSA [93] is the combination of the original DRG [91] method with (error propagation) EP [92] and SA, and has shown the best reduction efficiency among DRG-based methods [93]. The DRGEPSA method firstly evaluates the coupling relationship among species using a directed graph and then removes unimportant reaction paths based on the error propagation down the pathway, thus the stiffness of multi-step mechanisms can also be soothed.

In this study, a skeletal reduction based on Dagaut's detailed mechanism [94] for China Daqing RP-3 aviation kerosene was conducted using DRGEPSA method. Then DES modeling based on the skeletal kerosene mechanism is employed for the reacting flow in a full-scale scramjet combustor, which has been experimentally tested in a longtime direct connect supersonic combustion test platform (abbreviated as DTZ) in Chinese Academy of Sciences. Experimental measurements of static pressure and wall heat flux on the full-scale combustor assembly including isolator, combustor and expander were compared to validate the modeling results. Analysis on the integrated flow fields are presented to reveal the influence of fuel equivalence ratio on the supersonic flow and combustion characteristics which have not been measured experimentally.

\section{Numerical models}

\section{A. Turbulence model}

To reduce the computational cost in modeling the wall boundary layers, a hybrid Reynolds-averaged NavierStokes / large-eddy simulation (RANS/LES) technique known as Detached Eddy Simulation 97 (DES97) [96, 97] is applied. The background RANS model as one-equation Spalart-Allmaras model [98], which is set to cover the full wall boundary layer through well-designed inflation grid layer. The boundary layer is estimated firstly based on a pre-trial modeling, then the inflation layer is set to have a total thickness of around $3 \mathrm{~mm}$. The Spalart-Allmaras model is initially designed for the modeling of wall bounded flows in aerospace applications [98], and shows good predictive accuracy for boundary layer with negative pressure gradient. Since only one additional variable known as modified turbulent kinematic viscosity is required to solve, the Spalart-Allmaras is relative simple and thus computationally efficient. The model contains a wall destruction term to reduce the turbulent viscosity of laminar sub-layer and logarithmic sub-layer, ensuring a smooth transition from laminar to turbulent status [99]. In DES97, the length scale $d$ determines in a large degree the order of magnitude of the production and destruction of turbulent viscosity. In the original Spalart-Allmaras model near-wall distance $\mathrm{d}_{\text {wall }}$ is used as the length scale, while in DES97 the length scale is calculated as

$$
d=\min \left(d_{\text {wall }}, C_{D E S} \Delta_{\text {grid }}\right)
$$

where $\Delta_{\text {grid }}$ is the grid size calculated as the cube root of the grid volume or the largest dimension, and the coefficient $\mathrm{C}_{\mathrm{DES}}=0.65$ [100]. Usually the RANS mesh has a high aspect ratio in the boundary layer, i.e. the grid size parallel to the wall is much larger than the boundary layer thickness, to ensure the whole boundary layer is modeled in RANS mode according to the definition of length scale. Note that although the concept of DES was initially proposed with the one-equation Spallart-Allmars as its background RANS model [97], the RANS model can be replaced by any turbulence model that has an appropriately defined turbulence length scale and is a sufficiently localized model, e.g. Menter's SST two-equation model [65, 101]. In addition, there are some implementations of DES, such as DDES [101, 102] and IDDES [103, 104], allow for regions to be explicitly designated as in RANS or LES mode, and accordingly the current transition based simply on the distance function is classified as DES97. However, in DDES or IDDES approaches, the switch function not only depends on the grid but also of the local solution, thus a careful calibration for the switching parameters are required. Since no previous calibrations have been conducted for a wide range of high-speed compressible flows, in this study the simple DES97 is used.

The Favre-filtered or Favre-averaged Navier-Stokes equations including transport equations for individual species and sensible enthalpy are solved in a uniform framework by equally treating the turbulent viscosity in RANS and the subgrid scale (SGS) viscosity in LES. The Boussinesq hypothesis is used to relate unresolved stresses to the rate of strain of the resolved velocity field, i.e. a functional SGS model is used to dissipate turbulent kinetic energy at a rate mimicking the real physical value. Meanwhile, the gradient diffusion models with constant Prandtl and Schmidt numbers are used to account for the heat and mass diffusions due to unresolved turbulent eddies. The LES is closed also by the Spalart-Allmaras one-equation mixing length model through setting the length scale as $\mathrm{C}_{\mathrm{DES}} \Delta_{\text {grid }}$ in the LES region. 


\section{B. Turbulent combustion model and reduced kerosene mechanism}

Understanding of the flame regime in scramjet combustors is crucial for the choice of turbulence chemistry coupling model. The difference in the time and spatial scales of turbulent flow and chemical reactions determines the micro mixing and reaction process of the fuel, leading to different flame regimes. The turbulent chemistry interaction (TCI) in supersonic combustors depends not only on the flow condition, but also is affected by the fuel type $[71,105]$. In the Da (Damkohler number) - Re (Reynolds number) diagram shown in Fig. 1, the non-premixed flame in scramjet combustors can be divided into three typical regimes, i.e. wrinkled laminar flames $\left(\mathrm{Da}>1, \delta_{l}<l_{k}\right.$, $\delta_{l}$-flame thickness, $l_{k}-$ Kolmogorov scale), flamelets in eddies $\left(l_{k}<\delta_{l}<l_{l}, l_{I}\right.$-integral turbulence scale) and distributed reactions $\left(D a<1, \delta_{l}>l_{I}\right)$ [106], denoted respectively by A, B and C in the diagram. In the typical flight conditions of scramjets, the flame thickness $\delta_{l}$ in the combustor is generally between Kolmogorov scale $l_{k}$ and Taylor scale $l_{\lambda}$. $\delta_{l}$ is close to $l_{\lambda}$ at low inlet pressure and temperature, but gradually tends towards $l_{k}$ with the increasing of inlet pressure and temperature [107]. In addition, compared with subsonic flows, the compressibility drives the transfer of kinetic energy from larger to smaller scales at a faster rate (i.e. a steeper slope in the scaling law of kinetic energy transfer), and the dissipative eddies (i.e. those in Kolmogorov scale) are larger in high Mach number supersonic flows [71]. The high compressibility also increases collisional frequency and results in faster kinetics and thus higher flame speed and thinner flame [71]. Thus in scramjet combustors, the flame thickness may become smaller than the smallest turbulent eddies, which hence can only wrinkle the flame front to form corrugated flame rather than thicken the flame thickness through entering the reaction zone. For hydrogen fuels with small ignition delay time scale, experimental data and theoretical calculation show that most of the supersonic combustion region is in the regime of wrinkled laminar flames $(\mathrm{Ki}<1)$ or the upper regime of flamelets in eddies $(1<\mathrm{Ka}<100)$, where flamelet based turbulent combustion models are correct or approximately applicable [71, 105]. Whereas for complex hydrocarbon fuels (e.g. kerosene), the time scale of chemical reactions is close to that of turbulence eddies, all the combustion region is in the regime of flamelets in eddies $(\mathrm{Ka}>1)$, where the micro interactions between turbulence chemistry within the subgrid scale should be modeled by an approximate turbulent combustion model to close the filtered reaction rate term in the filtered species equations. Besides, there are subsonic combustion regions in the scramjet combustors since the combustors may run in ramjet mode under a certain fuel equivalence ratio, the nonuniform combustion condition can results in local regions in different flame regimes, therefor the selected turbulent combustion model should cover different flame regimes.

In this study, the PaSR (Partially Stirred Reactor) model initially proposed for internal engine combustion [108, 109] is used to account for the effect of mixture imperfections on chemical reaction rates. PaSR model is an extension of the classic EDC (Eddy Dissipation Concept) model $[110,111]$ but has a more accurate prediction on flame structures [112]. In PaSR, the final filtered reaction rate $\omega_{t}$ is mutually determined by the characteristic times of chemical reactions $\tau_{c}$ and turbulent micro-mixing $\tau_{\text {mix }}$,

$$
\omega_{t}=\omega_{l} \frac{\tau_{c}}{\tau_{c}+\tau_{\text {mix }}}
$$

where $\omega_{l}$ is the laminar reaction rate calculated using the filtered quantities, micro-mixing time is the same order of magnitude of Kolmogorov time scale $\tau_{\text {mix }}=C_{\text {mix }}\left(\frac{v_{\text {eff }}}{\epsilon}\right)^{1 / 2}$ with $C_{\text {mix }}=1.0$. From the above formula, the PaSR is a blending of quasi laminar model and eddy dissipation model (EDM) [113] depending the absolute dominance of chemistry or mixing in the rate control. In the DES based on Spalart-Allmaras model, the dissipation rate of turbulent kinetic energy is calculated as $\epsilon=2 v_{\text {eff }}\left|S_{i j}\right|^{2}$, were $S_{i j}$ is the strain rate. The characteristic chemical time is calculated as the reciprocal of elements of Jacobian matrix

$$
\tau_{c}=\left.\left(\frac{\partial \omega}{\partial c}\right)^{-1}\right|_{c=c_{i}} \approx \frac{\sum_{i} c_{i}}{\sum_{i} \omega_{i} / N_{r e c}}
$$

where $c_{i}$ is the initial concentration of species $i, \omega_{i}$ is the total production rate of species $i$ summarized from all related element reactions, $\mathrm{N}_{\text {rec }}$ is the total number of element reactions. 


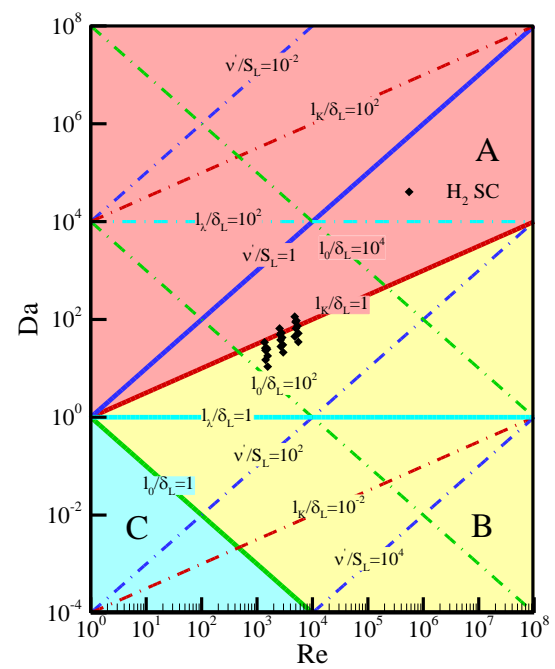

Figure 1. Non-premixed flame regimes in scramjet combustors

The prior problem to conduct numerical modeling of supersonic combustion based on kerosene is to find proper surrogates to simulate the complex multi-component hydrocarbon fuel, which usually has a component number larger than 1000 and the mole fraction of individual component is usually less than $10 \%$. The major components of kerosene type fuels (e.g. Jet-A1 and JP-8) are straight chain paraffins, branched chain paraffins, cycloparaffins, aromatics and alkenes, most in the molecular formula of $\mathrm{C}_{7}-\mathrm{C}_{16}$ [114]. In addition, the composition of each kerosene type fuel also varies with the band and the producing area.

Since 2000, the institute of mechanics (Chinese academy of sciences) has conducted extensive research on the thermophysical properties and combustion characteristics of China RP-3 aviation kerosene [81]. Chromatographic analysis shows that China Daqing RP-3 consists of $92.5 \%$ saturated hydrocarbons, $0.5 \%$ unsaturated hydrocarbons and 7\% aromatics, and the critical temperature and pressure are $630 \mathrm{~K}$ and $2.4 \mathrm{MPa}$ respectively [115], i.e. similar with Jet-A in both chemical composition and thermophysical properties. Therefore the combustion modeling based on China RP-3 aviation kerosene usually adopts directly the mechanisms developed for Jet-A and JP series aviation kerosenes. Analysis based on the principle of extended corresponding states (ECS) [116] shows that the three-species surrogate proposed by Dagaut et al. [95, 117] can accurately simulate the thermophysical and transport properties of China RP-3 kerosene, including those in supercritical state. In the latest release of detailed mechanism, Dagaut et al. [94] updated the surrogate compositions on the basis GC (gas chromatography) and GC/MS (gas chromatography / mass spectrometry) multidimensional analyses. In this study, the updated surrogate will be adopted to simulate the chemical composition of China RP-3 kerosene, and reduction on the corresponding mechanism will be conducted for the typical working condition range of scramjet combustors within a given error tolerance.

The mechanism reduction for RP-3 kerosene is conducted with the aid of computer program through a trial and error procedure, which mainly consists of three steps.

1) Using the directed relation graph with error propagation (DRGEP) method to remove unimportant species in the original detailed kerosene mechanism until the error in ignition delay reaches the maximum allowance. Firstly, choose appropriate target species, such as fuel surrogate species, oxygen, nitrogen and the final products (e.g. water vapor and carbon dioxide) according to the reaction path analysis for kerosene combustion in the combustor. Then a graph search in the network composed of interconnecting element reactions in the kerosene mechanism is performed to build the dependency paths for all species from the user-specified target species. Along each reaction path, calculate the direct interaction coefficients (DICs) between adjacent species, then cumulatively multiply all the intermediate DICs to obtain the path interaction coefficient (PIC). The maximum of all PICs between the target and each species of interest is defined as the overall interaction coefficient (OIC), which distinguishes the relative importance of all the graphic search paths connected the target and the examined species. Remove unimportant species in the detailed kerosene mechanism should their OICs fall below the an automatically-determined OIC threshold $\varepsilon_{\text {OIC }}$, and eliminate reactions participated by those already removed species. Calculate the ignition delay based on the reduced mechanism using the SENKIN package [118] distributed with CHEMKIN-III under the typical thermodynamic conditions of scramjet combustors, if the ignition delay error falls within the maximum 
allowance, then increases the OIC threshold in a small step to remove more unimportant species until the ignition delay reaches the maximum allowance, i.e. a user-specified error limit e.g. 50\%.

2) In the previous DRGEP reduction phase, part of limbo species have been retained through increasing the OIC threshold by a small factor of e.g. $\mathrm{e}^{0.1}$. Then sensitivity analysis on those limbo species in the range of $\left[\varepsilon_{\text {OIC }}, \varepsilon_{\text {OIC }} e^{0.1}\right]$ further removes intermediate species and corresponding element reactions. Firstly calculate the ignition delay errors when those limbo species are removed one by one from the original detailed mechanism, retain those with induced errors higher the user-specified error limit, and sort the remaining limbo species in ascending order according to their induced errors. Then the global error is calculated when each of those remaining limbo species is removed in order from the mechanism produced in the previous DRGEP phase, until it reaches the user-specified error limit. Following the sensitivity analysis phase, a final skeletal mechanism consisting of 39 species and 153 reactions is reduced form the original 2185 species and 8217 reactions [94] with approximately 50\% maximum error in ignition delay.

3) Through the above directed relation graph with error propagation and sensitivity analysis (DRGEPSA) phases, only the error in ignition delay is controlled within an allowed limit while the other kinetic properties have not been validated. Fig. 2 shows the comparisons of kinetic properties between the skeletal mechanism and the original mechanism. Fig. 2 (a)-(c) are the modeling results of a closed homogeneous reactor, where reaction occurs in a constant-pressure adiabatic container with well-stirred mixture in unity equivalence ratio. The container pressure is maintained at $1 \mathrm{~atm}$ and the initial mixture temperatures are set as $1200 \mathrm{~K}, 1500 \mathrm{~K}, 1800 \mathrm{~K}, 2100 \mathrm{~K}$ and $2400 \mathrm{~K}$ for parameter study. Here the ignition is defined when the temperature reaches a value of $400 \mathrm{~K}$ above the initial temperature. Fig. 2 (d) is the modeling result of a one-dimensional freely propagating flame model, where different equivalence ratios from 0.7 to 1.5 are set. In overall, the adiabatic flame temperature, total heat release, ignition delay and laminar flame speed predicted by the skeletal mechanism show an overall good accordance with those predicted by the original detailed reaction mechanism. The total heat release determines the heat addition to the combustor and thus the peak pressure, while the ignition delay determines the downstream lifting distance of main reaction zones, which usually corresponds to the location of peak pressure, thus an accurate skeletal mechanism is of vital imnortance for the flowfield predictions in the supersonic combustor
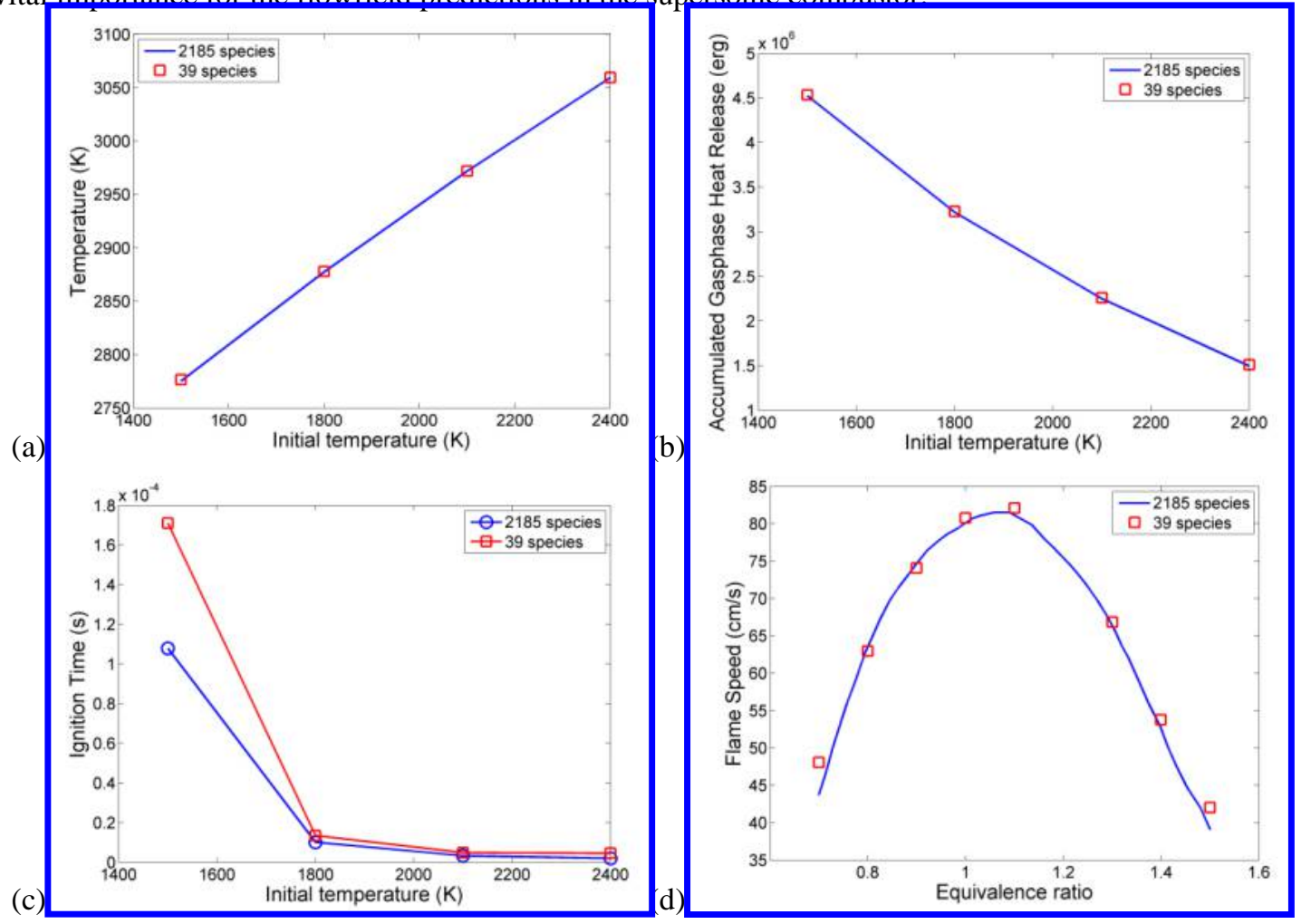

Figure 2. Comparisons of kinetic properties between the reduced skeletal mechanism (39s/153r) and the original detailed mechanism (2185s/8217r), (a) flame temperature, (b) total heat release, (c) ignition delay, (d) laminar flame speed 
Detailed mechanisms for the oxidation hydrocarbon fuels usually contain hundreds of or thousands of element reactions, even if the skeletal mechanisms contain at least more than one hundred reactions, based on which threedimensional reacting flow modeling requires huge computational resources and the existent computer technology cannot meet the practical demand in solving engineering problems. To further speed the solving of large hydrocarbon chemistry systems, In Situ Adaptive Tabulation (ISAT) method [119, 120] is adopted to tabulate and map the initial and final thermodynamic states in the multidimensional space coordinated by thermodynamic parameters. ISAT firstly solves the final thermodynamic state by direct integration (DI) for a given initial thermodynamic state after a certain reaction time, then stores the initial and final states in an in situ table. In the subsequent calculations, the time consuming integration process is replaced by simple algebraic interpolation on the final state parameters corresponding to the initial state parameters most matchable to the current thermodynamic parameters. It is worthwhile to note that most reacting system involves only a subspace of the complete multidimensional space coordinated by thermodynamic parameters, which depends on the local combustion conditions, such as the reaction mechanism, thermophysical properties and turbulence characteristics, and cannot be determined beforehand. In order to save storage space and improve the efficiency of subsequent lookups, ISAT table need to be progressively built during the modeling process. In parallel computations, the ISAT table is built in situ for each dividing computational zone, and there are no ISAT data interexchange among the processors. In scramjet combustors, the main reaction zone lies around the jet wake and the cavity, building separated ISAT table helps to reduce the CPU communication cost and improve the computation speed. With the completing of the table, most of the direct integrations can be avoided and thus the solving of large hydrocarbon reacting systems can be greatly accelerated.

\section{Solver setup and numerical details}

The modeling is performed based on an in-house developed supersonic combustion solver, AstroFoam, which is based on Finite Volume Method (FVM) to be compatible with the unstructured meshes generated for supersonic combustors in complex geometry shape. AstroFOAM is developed on the basis of a compressible rhoCentralFoam solver distributed with the OpenFOAM v2.3.0 CFD package [121], mainly through adding the features of multispecies transport and multi-component reaction. Correspondingly, the sensible enthalpy equation instead of the sensible internal energy equation is solved in AstroFoam for the modeling of transient reacting flows. The inviscid flux scheme in the rhoCentralFoam solver, i.e. the second-order semi-discrete Kurganov-Tadmor (KT) central scheme [122], has been demonstrated to be non-oscillatory in capturing flow discontinuities (e.g. shock waves) while computationally efficient since neither Riemann solvers, Jacobians nor characteristic decompositions are involved [123]. Similar OpenFOAM solvers have been developed to study subsonic flows by Vuorinen et. al. [124] and Baba-Ahmadi and Tabor [125], as well as supersonic flows by Vuorinen et. al. [126, 127] and Fureby et. al. [3, 10]. In AstroFoam, the flux discretization is extended to second order spatial accuracy by reconstructing the primitive variables on interfaces using Total Variation Diminishing (TVD) scheme, for which the Minmod limiter is used in this study. The molecular viscosity is calculated based on Sutherland formula, and unity Prandtl number and Schmidt number are applied for the calculation of thermal and mass diffusion coefficients.

The computational domain consists of an isolator, a combustor and an expander in full size of the square supersonic combustor that has been experimentally studied. To relief the prohibitive computational cost, only half of the actual combustor (split in the spanwise direction) is used as the computation domain with symmetrical boundary condition applied to the splitting plane. Although the domain splitting will restrain the three-dimensional evolution of coherent structures in some extent, its influence on the average flow fields is generally considered small. The mesh is generated using the Cartesian CutCell method, which uses a patch independent volume meshing approach with surface mesh automatically created from boundary of volume mesh, thereby producing high-quality and uniform hexahedral grid cells for most internal volume of the computational domain, while tetrahedron, wedge or pyramid grid cells are filled only in the border regions or corners with large local curvature. Different cell size can be specified for the three combustor parts and boundary surfaces, then the mesh is then adaptively refined based on the local size function values. The minimum cell size is $0.25 \mathrm{~mm}$ distributed mainly around the fuel injectors, and the rest domain is meshed with the maximum cell size of $1 \mathrm{~mm}$ and a size growth rate of 1.2. The total cell number in the half-splitting combustor domain is 20.55 million. Inflation layers are laid on the lateral wall boundaries with the near wall nondimensional cell size $\mathrm{y}^{*}<1$. The inflation layers have a total thickness of $3 \mathrm{~mm}$ which is approximately the boundary layer thickness estimated from a prior modeling. The cells in the inflation layers have a high aspect ratio, i.e. the cell dimension parallel to the wall is much larger than that normal to the wall, to ensure the DES model acts as a RANS model there. Grid quality analysis shows that (1) the proportion of hexahedral cells is close to $100 \%$, thus ensuring high solving efficiency and convergence rate; (2) $99.9 \%$ of the cell has a skewness smaller than 0.05, indicating approximate equilateral cells in shape; (3) $99.9 \%$ of the cells have orthogonal quality higher than 0.963 , which can improve the accuracy in face interpolation. The excellent grid quality demonstrates 
that the CutCell method can mesh complex geometric features without compromising the overall grid quality. In the following analysis, the coordinate origin locates at the lower left corner of the square combustor, $\mathrm{X}$ represents the streamwise direction, $\mathrm{Y}$ represents the height direction, and $\mathrm{Z}$ represents the spanwise direction.

The experimental configurations corresponding to the current modeling setup are shown in Table 1 . The experiment was conducted on a long-time direct-connect supersonic combustion test facility (abbreviated as DTZ in the following) built in State Key Laboratory of High Temperature Gas Dynamics (China). DTZ consists of an air supply system, a nozzle section, a combustor assembly, a water-cooling system, a data acquisition and control system, a fuel heating and delivery system. Static pressure and wall heat flux were measured during the whole test period by pressure transmitters and heat flux sensors attached to the combustor assembly. The incoming vitiated air, which is supplied by burning hydrogen in air with oxygen replenishment in unity equivalence ratio, has a raised stagnation temperature of $1300 \mathrm{~K}$ and a Mach number (Ma) of 2.0 at the entrance of isolator. The compositions of vitiated air are $\mathrm{N}_{2}$ in $65.2 \%$ mole fraction, $\mathrm{O}_{2}$ in $20.9 \%$ and $\mathrm{H}_{2} \mathrm{O}$ in $13.9 \%$, with more water content than the high enthalpy flow encountered in a real flight test. The fuel equivalence ratio is changed from $0.8,1.0$ to 1.2 while the incoming vitiated air is maintained at the same flow conditions, in order to investigate the influence of fuel equivalent ratio on the combustion characteristics in the combustor. The fuel is injected from 2 upstream and 2 downstream (in the half-sectioned modeled combustor) 2.8-mm-diameter circular injectors oriented normal to the wall (approximately normal to the supersonic crossflow since the upper wall has a small expanding angle) and before each belonging cavity. Hydrogen is used as ignition fuel in each test and turned off once the kerosene has been ignited.

The inlet boundary conditions on the isolator inlet and the fuel injectors are set according to the experimental configurations listed in Table 1. Open boundary condition is applied to the expander outlet, where zero gradient is used for outflow and ambient flow parameters are specified should backflow occur. Nonslip boundary condition is applied on the combustor walls. In the experiment, the combustor walls were cooled by a water-cooling system to maintain a low wall temperature far below the material melting point. The thermal condition on the wall boundaries is estimated by an Integrated Gas-liquid-solid Thermal Analysis Model for Hydrocarbon based Regenerative-Cooled Supersonic Combustor developed by the authors' group. Turbulent viscosity on the non-slip combustor walls is modeled by a wall function model, which bridges the viscosity-affected sublayer (VASL) and the fully turbulent region through formulating the turbulent viscosity as a semi-empirical expression,

$$
\mu_{\mathrm{t}}=\mu\left(\frac{\mathrm{y}^{*} \mathrm{k}}{\ln \left(\mathrm{Ey}^{*}\right)}-1\right)
$$

where $\mathrm{y}^{*}$ is the nondimensional distance from the wall, Von Karman constant $\kappa=0.4187$, empirical constant $\mathrm{E}=9.793, \mathrm{k}$ is the turbulence kinetic energy at the wall-adjacent cell centroid.

Table 1. Experimental and modeling configurations

\begin{tabular}{|c|c|c|c|c|c|c|c|c|}
\hline \multicolumn{4}{|c|}{ Air } & \multicolumn{4}{|c|}{ Kerosene } & \multirow{2}{*}{$\frac{\text { Injector }}{\text { Location }}$} \\
\hline $\mathrm{P}_{0}$ & $\mathrm{~T}_{0}$ & $\mathrm{Q}_{\text {air }}$ & $\mathrm{Ma}$ & $P_{f}$ & $\overline{T_{f}}$ & $\mathrm{Q}_{\text {fuel }}$ & $\Phi$ & \\
\hline $\mathrm{MPa}$ & $\mathrm{K}$ & $\mathrm{g} / \mathrm{s}$ & & $\mathrm{MPa}$ & $\mathrm{K}$ & $\mathrm{kg} / \mathrm{s}$ & & \\
\hline 0.4205 & 1300 & 2576.7 & \multirow{3}{*}{2.0} & 2.87 & 769 & 0.1236 & 0.8 & \multirow{3}{*}{$\begin{array}{l}\text { Upstream } \\
\text { downstream }\end{array}+$} \\
\hline 0.4205 & 1300 & 2576.7 & & 3.79 & 768 & 0.1557 & 1.0 & \\
\hline 0.4205 & 1300 & 2576.7 & & 4.90 & 772 & 0.1946 & 1.2 & \\
\hline
\end{tabular}

\section{Results and discussion}

\section{A. Pressure fields}

Figure 3 shows the static pressure contours predicted for the cases with different fuel equivalence ratios. An obvious observation is that the pressure rise due to combustion propagates towards the isolator inlet with increasing equivalence ratio. Several oblique shocks in train structure can be observed in the isolator from the abrupt pressure rises, indicating a thin boundary layer developed since the isolator inlet. High pressure mainly distributes around the upstream injector in the combustor, and the high pressure region enlarges as well with increasing equivalence ratio. Whereas, the pressure rise due to combustion around the downstream fuel injector is unobvious, with only a small pressure rise region observed immediately after the downstream injector for the equivalence ratio of 1.2. Fig. 4 compares the time-averaged static pressure profiles predicted by the current modeling with those measured in the tests. The agreements are generally good for all the modeling cases whether in the general trend or the peak value. Note that the inlet conditions for the incoming vitiated air is influenced by the combustion efficiency of upstream heater and also the roughness of converging-diverging nozzle, thus the inlet pressure varies within $10 \mathrm{KPa}$ in the 
tests, which is one of the uncertainties in the modeling setup. The locations of initial pressure rise near the isolator inlet are well predicted. Then the pressure increases almost linearly towards the combustor inlet. There are noticeable abrupt pressure rises due to the first oblique shock wave in the cases with $\phi=1.0$ and 1.2 both in the modeling and the tests. The peak pressure located at the upstream injector is slightly overpredicted by around 10 $\mathrm{KPa}$. The pressure ratio between the peak pressure and the initial pressure increases from $4,4.5$ to 5 for the three equivalence ratios. There are slight pressure rises at the downstream injector, corresponding to the small higher pressure rise regions observed in Fig. 3. The pressure rises at the expander outlet in the measured data are due to the upstream propagation of background pressure, which is ambient atmosphere pressure $(1 \mathrm{~atm})$ in the experiment while zero-gradient open boundary condition is applied for the outlet in the modeling

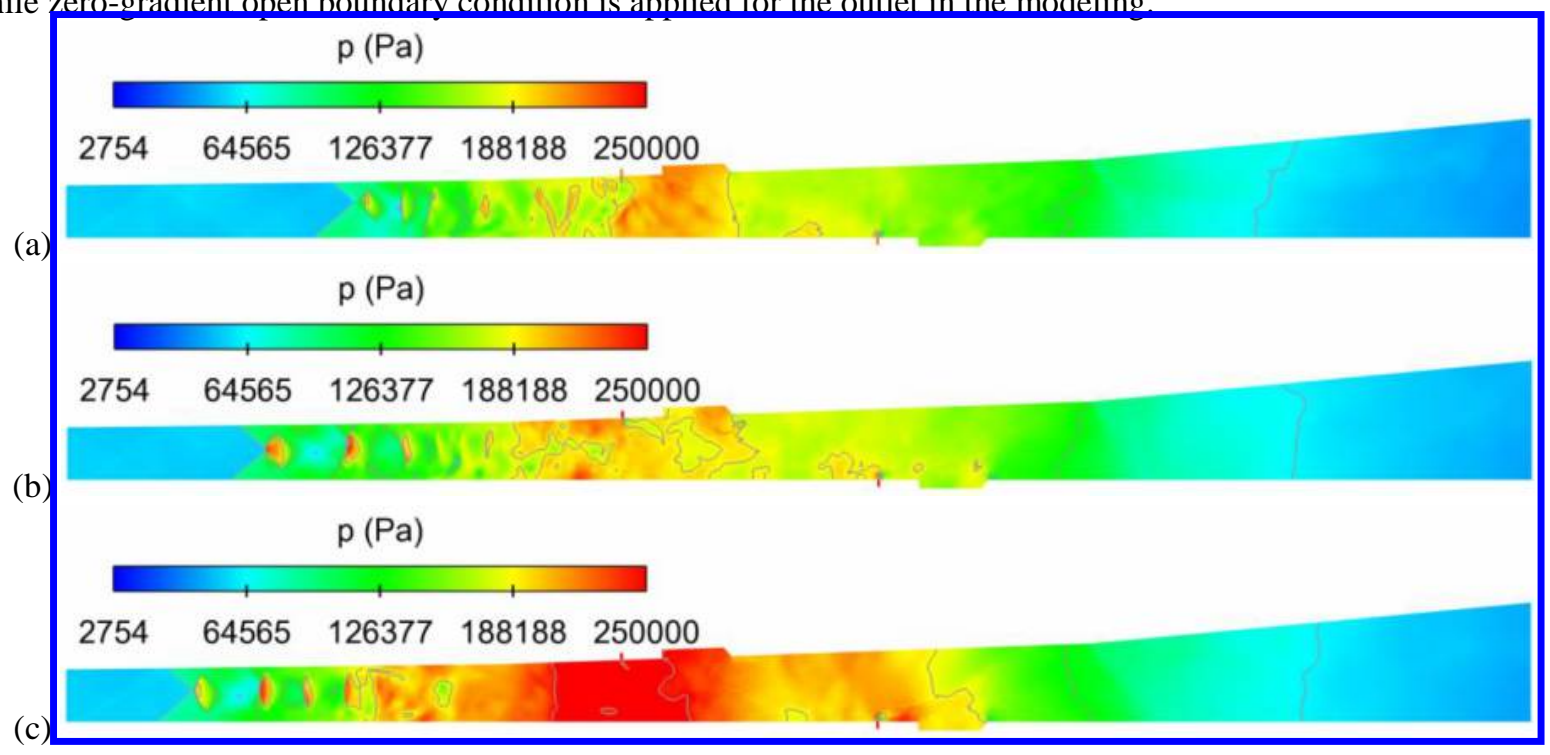

Figure 3. Instantaneous static pressure contours on the streamwise plane through one fuel injector $(\mathrm{Z}=57$ mm) for different fuel eouivalence ratios: (a) 0.8 , (b) 1.0 . (c) 1.2
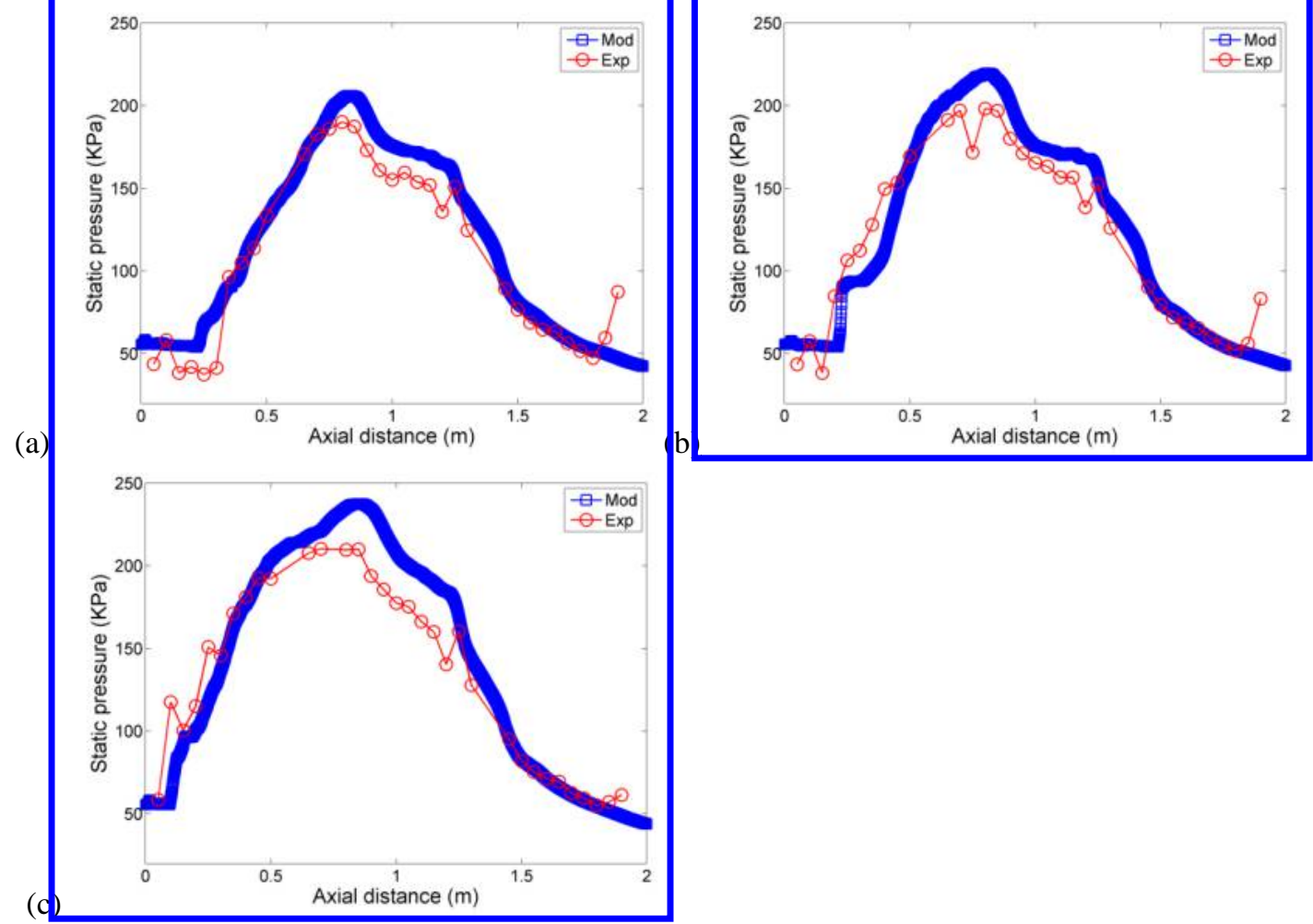

Figure 4. Time-averaged static pressure profiles on the centerline of the lateral wall ( $Y=35 \mathrm{~mm}$ ) for different fuel equivalence ratios: (a) 0.8 , (b) 1.0, (c) 1.2

American Institute of Aeronautics and Astronautics 


\section{B. Temperature fields}

Figure 5 shows the time-averaged temperature contours on the slices through one injector for different equivalence ratios. The maximum instantaneous temperature is around $2700 \mathrm{~K}$. The instantaneous distribution of conserved scalars, e.g. temperature and species concentrations, varies significantly with time, thus the mean fields are analyzed instead. The shock train in the isolator increases the static temperature of incoming air to above $1000 \mathrm{~K}$, which facilitates the initial chain reactions and the autoignition of supercritical kerosene. As can be seen, the fuel is not ignited immediately after the injector, but mainly oxidized since the cavity. The temperature in the wake region following the fuel injection has a lower temperature, which is caused not only by the expanding but also by the endothermic chain reactions there. Those initial chain reactions between the fuel injector and the cavity prepare radical pool for the subsequent ignition. The regions with high temperature (>1966 K) are distributed in the mixing layer following the cavities and attached to the walls. With the increasing of equivalence ratio, the upper hightemperature region thickens gradually and the lower high-temperature region expands towards both the cavity and the expander.

Figure 6 shows the instantaneous heat release distributions for the three equivalence ratios. The main reaction occurs in the mixing layer starting from the leading edge of the cavities, indicating the importance of cavity in the flame anchoring. There are generally three flame anchoring modes observed both in the modeling and experiments, i.e. (a) jet-wake mode, the flame resides in the jet wake immediately after the injector, (b) cavity mode, the flame resides in the mixing layer since the leading edge of cavity, (3) oscillation mode, the flame resides in the above two locations periodically. The jet-wake mode usually occurs for fuels (e.g. hydrogen) with short ignition delay or incoming flow with high enthalpy. For multi-component fuels, e.g. kerosene with large ignition delay, the most commonly encountered flame anchoring mode is the cavity mode, where the cavity acts the four roles of preheater, mixer, residing bay (low flow speed) and radical pool. The oscillation mode is seldom observed, but can occur at a medium ignition delay within a small marginal region and has been confirmed in an ethylene fueled test (results not shown here) conducted by the authors' group. As the equivalence ratio increases from 0.8 , the upstream reacting layer extends and corrugated by large-scale vortices. The heat release on the top of the downstream cavity is negligible compared with the upstream one for $\phi=0.8$. In addition to the reacting layer anchored at the leading edge of the downstream cavity, the downstream reaction zone is multi-layer for $\phi=1.0$ and 1.2. This is because that the downstream fuel jet is preheated by the upstream high-temperature mixing layer as shown in Fig. 5, and the fuel in the jet wake is ignited after some distance downstream, especially a co-exist jet-wake mode becomes apparent for $\phi=1.2$.

Figure 7 compares the predicted heat flux profiles with the measurements for the three equivalence ratios. The agreement in the general trends is good, but the peak and overall heat flux are both overpredicted. The heat flux on the isolator wall is well predicted. The heat flux has a sharp increase at the leading edge of the upstream cavity and then peaks in a small distance since the trailing edge, where large heat release usually occurs as shown in Fig. 6. Both the and measured predicted heat release has a plateau in the region between the upstream and downstream cavities, where the heat flux is overpredicted for about $20 \%$. The heat flux then decreases towards the outlet in the expander, where the heat flux is well predicted for $\phi=1.0$ but overpredicted by almost $50 \%$ for $\phi=0.8$ and 1.2 . The cavity effect on the predicted heat flux is not obvious, for example the small sharp rise observed in the measurements around the downstream cavity is not observed in the prediction. This is because the thermal boundary condition determined from the Integrated Gas-liquid-solid Thermal Analysis Model is based on a one-dimensional flow analysis, where the effect of cavities on the combustion cannot be well accounted for. The heat flux is generally sensitive to the thermal boundary condition and the thickness of turbulent boundary layer, thus an accurate description of the heat flux needs to accurately model the development of boundary layer, which is still a involved problem for supersonic flows due to the complex Shock Wave/Turbulent Boundary Layer Interaction (SWTBLI). Hot spots on the instantaneous heat flux distribution on the walls were observed in the modeling, due to the separated regions (appear as bubbles) caused by impinging shock wave strengthen the convective heat transfer [128].

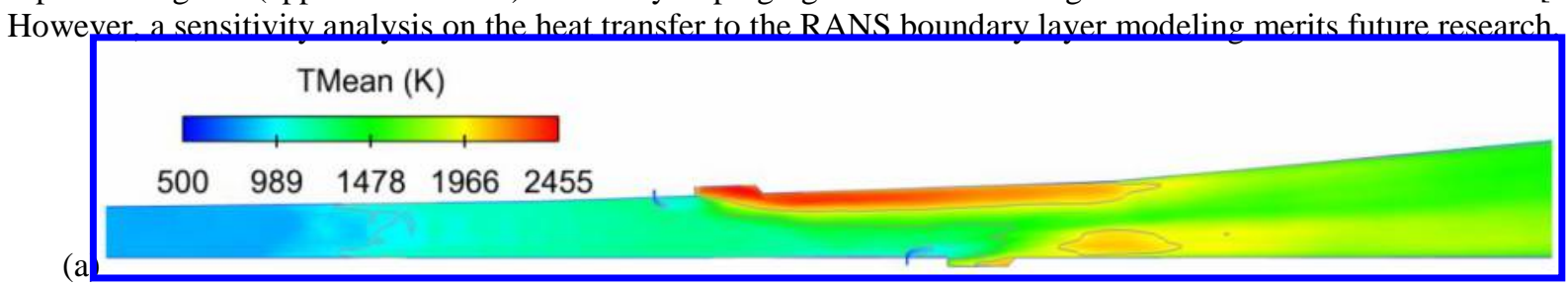




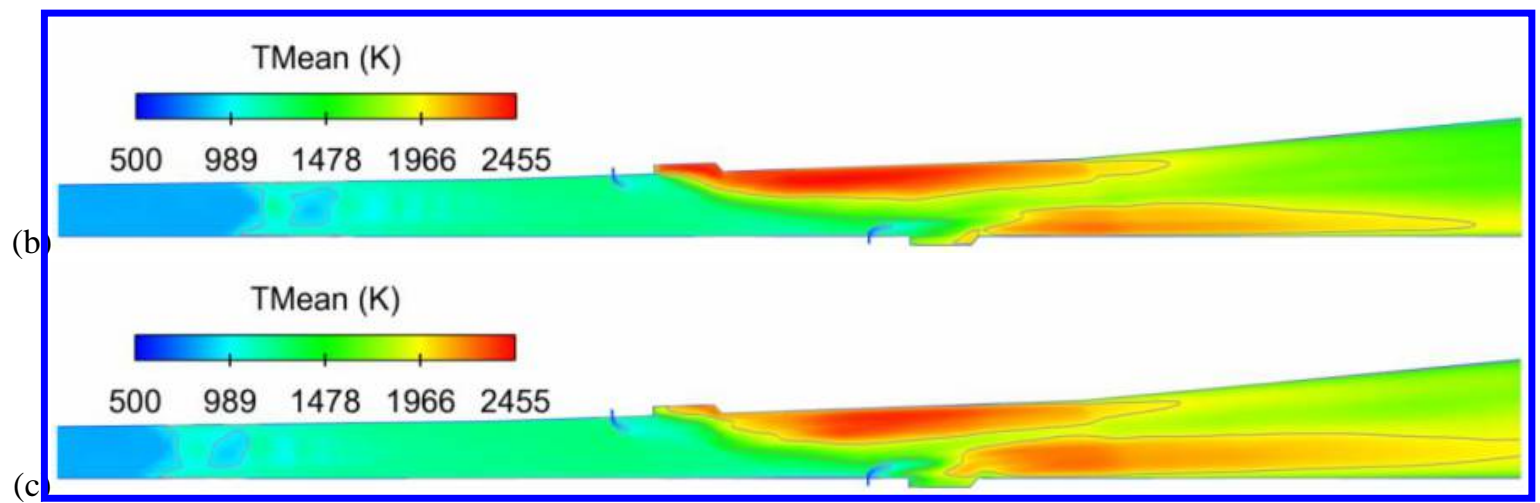

Figure 5. Time-averaged static temperature contours on the streamwise plane through one fuel injector $(Z=57$ $\mathrm{mm}$ ) for different fuel equivalence ratios: (a) 0.8 . (h) 1.0 . (c) 1.2

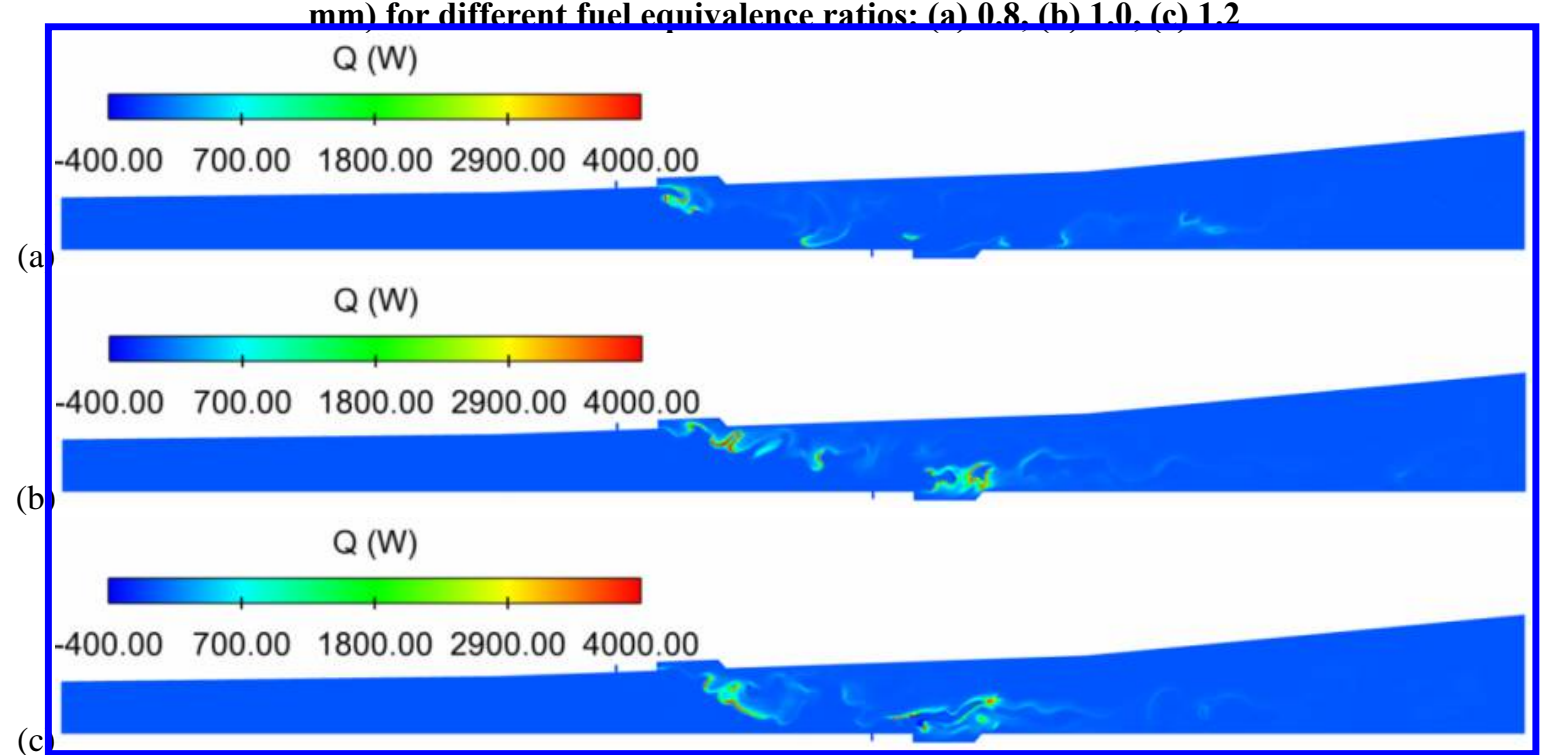

Figure 6. Instantaneous heat release rate distributions on the streamwise plane through one fuel injector $(Z=57 \mathrm{~mm}$ ) for different fuel equivalepce ratios: (a) 0.8 . (b) 1.0 (c) 1.2

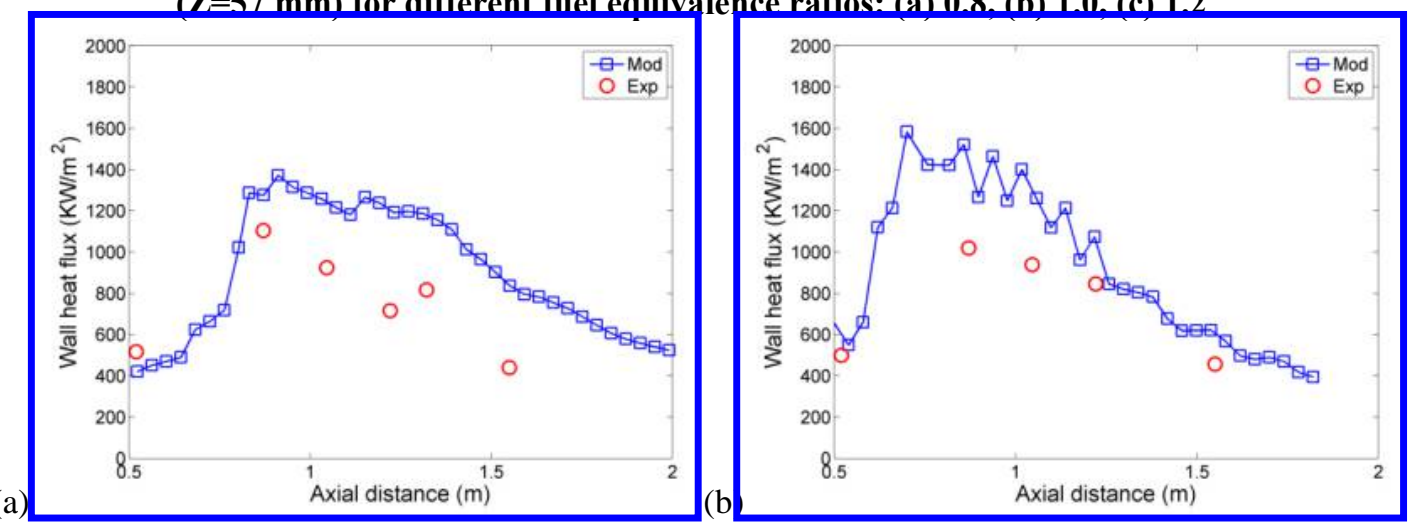




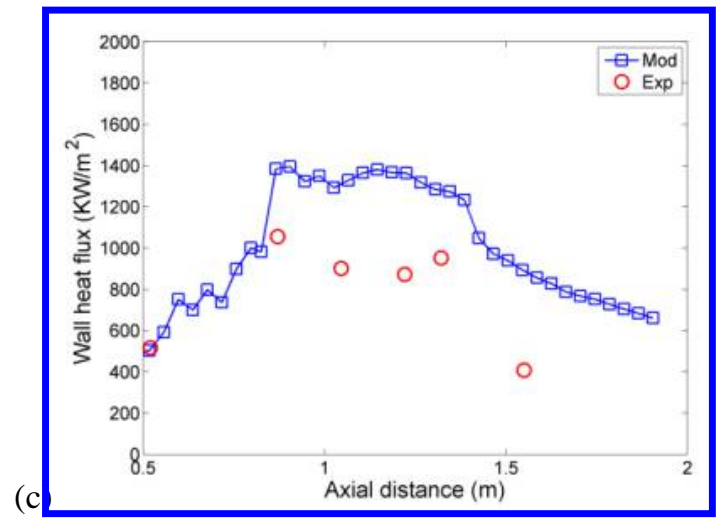

Figure 7. Instantaneous heat flux profiles on the upper wall for different fuel equivalence ratios: (a) 0.8, (b)

\section{Velocity fields and shock structures}

$$
1.0, \text { (c) } 1.2
$$

Figure 8 and 9 show the predicted instantaneous contours of velocity magnitude and corresponding Mach number for different fuel equivalence ratios. The flow is quite uniform before the first oblique shock wave in the isolator and the boundary layer is much thin. With the origination or the impinging of shock waves, the boundary layer is discontinuously thickened or separated by the negative pressure gradient imposed by the combustion pressure rise. Corresponding to the shock train, there are a succession of speeding regions in the remainder of isolator. The flow speed decreases significantly to even below $100 \mathrm{~m} / \mathrm{s}$ around the upstream injector and in the cavities, the low speed $(<390 \mathrm{~m} / \mathrm{s})$ region expands greatly as the equivalence ratio or heat release increases. While the flow is only slowdown in the fuel jet wake region and inside the cavity for the downstream, where the high-diverging-angle expander tends to relief the thermal choking in some degree. Due to the significantly low flow speed (locally $<100$ $\mathrm{m} / \mathrm{s}$ ) in the cavities, the flow residence time is of the order of $1 \mathrm{~ms}$, which is on the same order magnitude of the ignition delay of kerosene, implying a quasi-equilibrium reaction can be reached there to provide not only high temperature but also rich radicals for the flame anchoring.

The sound speed line in Fig. 9 delimits the supersonic and subsonic regions. As can be seen, most of the combustion occurs under subsonic condition and thus the scramjet combustor actually run a ramjet mode with the shock train acts as the first aerodynamic throat. At $\phi=0.8$, there are some discontinuous supersonic flow regions around the downstream cavity. The length of subsonic regions increases with increasing equivalence ratio. The flow is then reaccelerate to supersonic in the expander, implying a second aerodynamic throat is formed in the combustor due to the pressure rise around the unstream fuel iniector and cavity

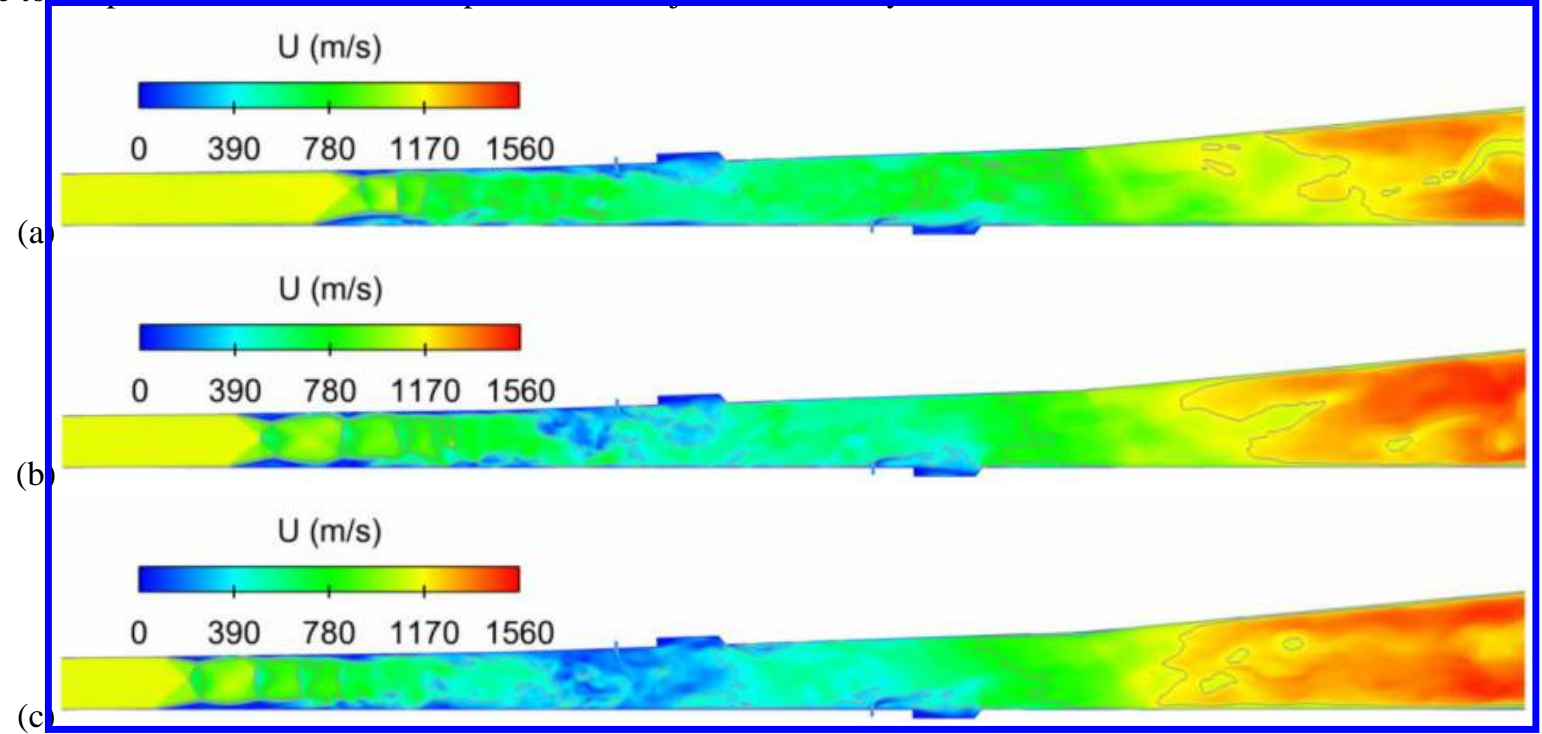

Figure 8. Instantaneous velocity magnitude contours on the streamwise plane through one fuel injector $(Z=57$ $\mathrm{mm}$ ) for different fuel equivalence ratios: (a) 0.8 , (b) 1.0, (c) 1.2 


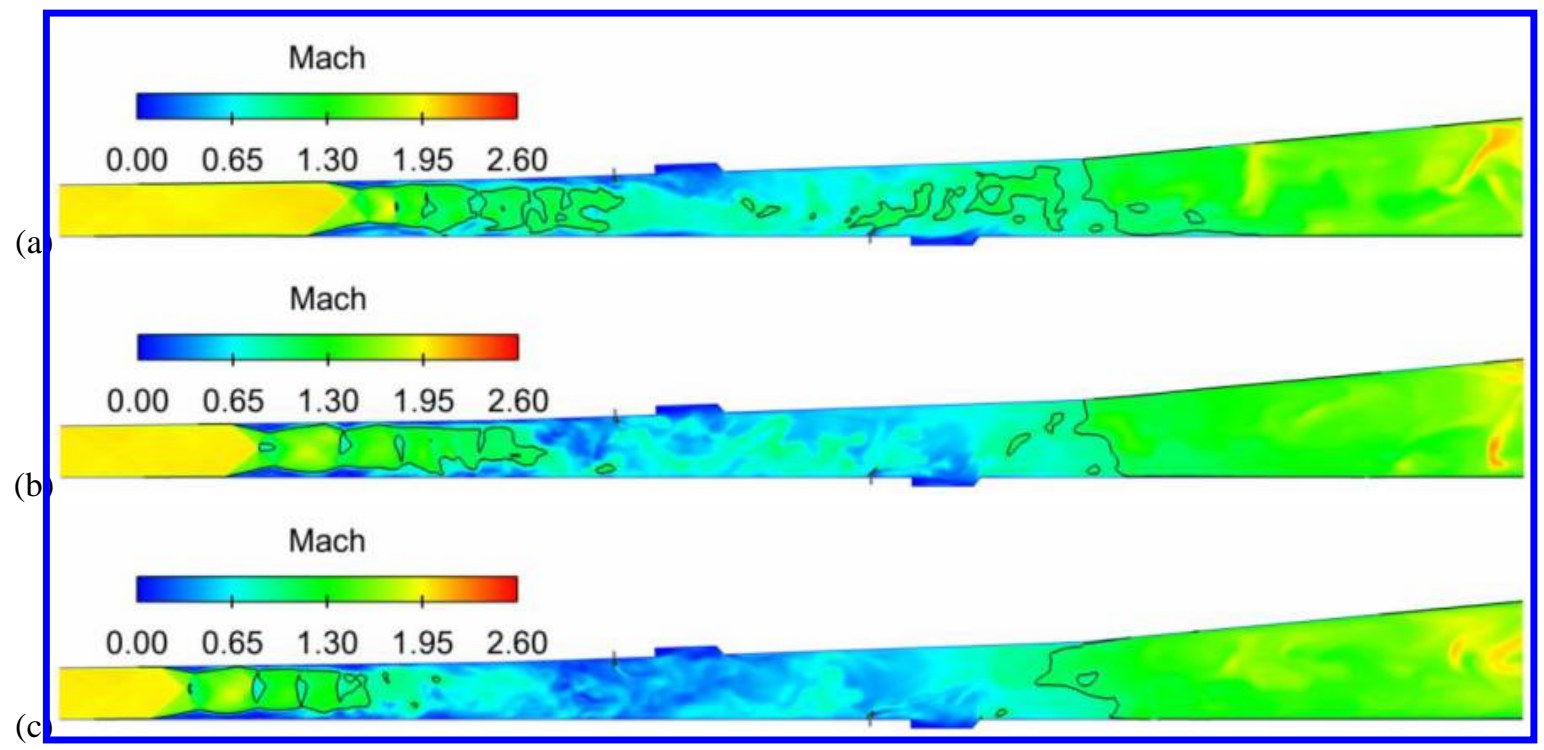

Figure 9. Instantaneous Mach number contours on the streamwise plane through one fuel injector $(\mathrm{Z}=\mathbf{5 7} \mathrm{mm})$ for different fuel equivalence ratios: (a) 0.8, (b) 1.0, (c) 1.2

Figure 10 shows Instantaneous magnitude contours of density gradient $(|\nabla \bar{\rho}|)$, which is similar to the schlieren images but without knife edge cutoff. Four types of flow regions with large variation in density are clearly shown, i.e. shock waves, fuel stream, reacting layer and boundary layer. At least four successive shock wave structures consisting the shock train can be observed in the isolator, and they propagates upstream as the equivalence ratio increases. The penetration height of the large-density kerosene fuel increases significantly. The reacting layer generally corresponds to the distribution of heat release rate in Fig. 6, where the flame is anchored at the leading edge of the cavity and extends over the cavity for one or two cavity length(s). The upstream reacting layer, as also shown in Fig. 5, can penetrate across the combustor in transverse direction and extends to reach the downstream jet wake, thus the downstream fuel is ignited before they entering the cavity and additional reacting layers appear over the downstream cavity. For the upstream part, the fuel stream interacts with the reacting layer rooting at the leading edge of cavity at a cross point, form which the flame can propagate upstream to ignite the fuel in the jet wake should the flame speed becomes high enough under certain conditions, e.g. high-enthalpy incoming flow shortens the ignition delay or the fuel stream is simply changed in compositions. Thereby, the intersection point act as an important bridging role in the oscillation flame-anchoring mode. The downstream fuel stream penetrates deeper thus does not intersect with the reacting layer starting from the cavity leading edge, because the momentum flux of the cross flow has been decreased by the upstream heat addition and wall friction [129, 130] while isotropic onedimension analysis indicates that a Mach number of $\sqrt{2}$, far beyond the current subsonic value, could achieve the maximum momentum flux [131]. Thickened or separated boundary layer can also be visualized in the end part of isolator and the combustor with large negative pressure gradient. while the houndary laver in the expander is thinner.

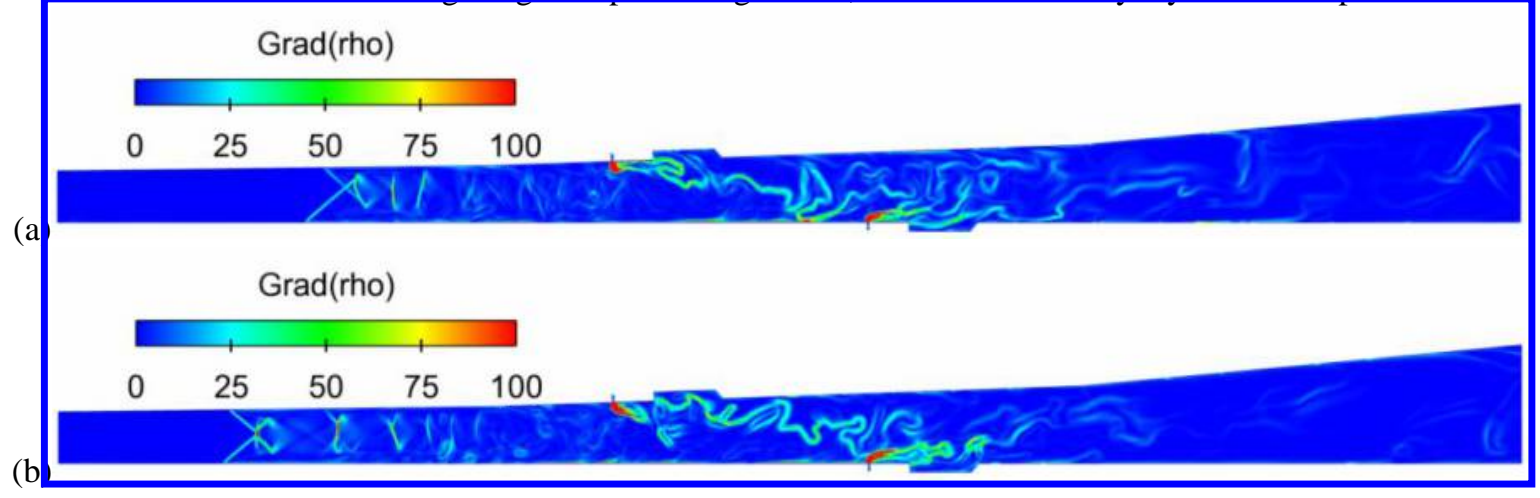




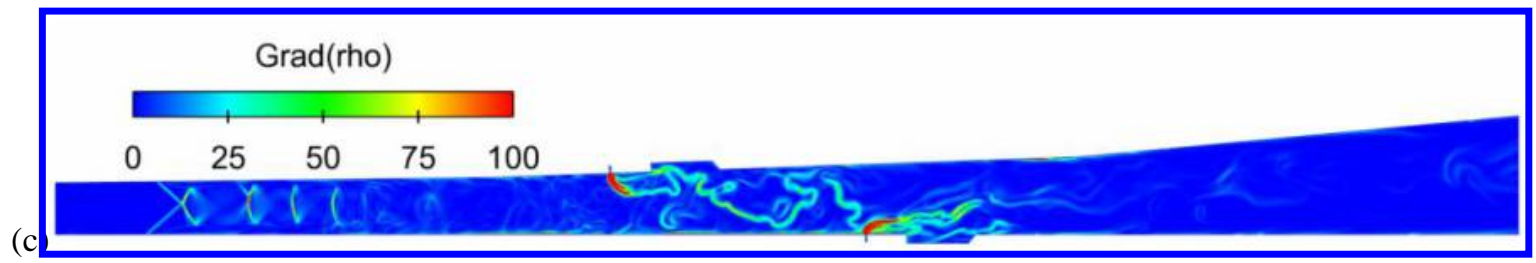

Figure 10. Instantaneous magnitude contours of density gradient $(|\nabla \bar{\rho}|)$ on the streamwise plane through one

\section{Turbulence fields}

fuel injector $(\mathrm{Z}=57 \mathrm{~mm})$ for different fuel equivalence ratios: (a) 0.8 , (b) 1.0, (c) 1.2

Figure 11 shows the instantaneous contours of vorticity magnitude for different equivalence ratios. With the increasing of equivalence ratio, the vorticity strengthens and broadens due to the increasing in combustion heat release and the distortion of crossflow by transverse jet with increasing penetration height. The vorticity distribution in the isolator denotes the basic shape of boundary layer along with the separated and detached flow regions, under the impinging of shock waves. The formation of shock wave, or so called pseudo shock wave (PSW), in the isolator is to rise the static pressure of cross flow in order to match the back pressure propagates upstream from the combustor. From this point of view, the negative pressure gradient, which counterbalances the forward momentum and finally separated or thicken the boundary layer, phenomenally caused by the shock waves but actually originates from the combustion pressure. As evidenced by the current modeling results, in the back part of isolator and in the combustor, boundary layer still thicken or separated without the origination or impinging of shock waves. With the increasing of combustion pressure rise, the boundary layer is firstly influenced by the negative pressure gradient, then the vorticity generation in the internal flow field in the upstream is enhanced, indicating the boundary layer acts as the key role in the information propagation from downstream to upstream for supersonic flows. The vorticity enhancement in the isolator will promote the turbulent mixing in the downstream combustor, which will further increase the combustion efficiency and thereby total heat release. The region with the most intense vorticity generation is in front of the upstream injector, corresponding to the pressure plateau in Fig. 3. Unlike in subsonic flows, vorticity distribution is not exclusively driven by vortex stretching, but also by baroclinic and expansion effects [71]. Between the upstream and the downstream cavities, the high vorticity generation is due to the baroclinic torque arisen by the combustion heat release. On the other hand, the expansion effect due to combustion tends to redistribute the vorticity in the combustor. Large-scale vortexes can be observed from the vorticity distribution in the expander, where no reaction occurs but only the mixing between the hot layers and the relative cold crossflow as shown in Fig. 5.

Figure 12 provides a detailed insight into the development of coherent structures in the full-scale scramjet combustor identified by the iso-surface of a positive value of the Q-criterion, which measures the balance between the magnitudes of vorticity and strain rate [132]. The successive oblique shock waves can be seen in the beginning of isolator, vortexes are formed since the origination of the first shock wave. One important behavior of vortexes is that then can be transported, merge, breakup and finally dissipate like distinct individuals. With the increasing of fuel equivalence ratio, the vortexes span upstream to the isolator, and the vortex structures in the combustor become richer both in the amount and the hierarchy. The vortexes in the isolator are generally streamwise and in large scales, then break up to small scales and in more random orientation in the combustor. The breakup of large-scale vortexes to small-scale twisted vortexes occurs to the location with the maximum combustion pressure in Fig. 3, i.e. around the upstream cavity for $\phi=0.8$ while around the upstream injector for $\phi=1.0$ and 1.2 . This is because the reduction in the through area $\mathrm{A}$ of aerodynamic throat by heat addition increases the turbulence Reynolds number as $\operatorname{Re} \sim \rho \mathrm{U} \sim 1 / \mathrm{A}$, therefore after the upstream cavity the generation of turbulent vortexes diminishes gradually and becomes trivial in the expander. It is noticed that vortexes in roller or $\Omega$ shape are formed near the wall boundary and in the cavity due to large shear stress there. Those vortexes originated from the boundary layer have low speeds compared with those forming in the internal field. The $\Omega$-shaped vortices are three-dimensional coherent structures resulting from the interaction between the boundary layer and the flow due to Kelvin-Helmholtz (K-H) instability. A large number of fine vortexes are formed due to the on-going breakup of large-scale vortexes and then dissipate gradually in the expander

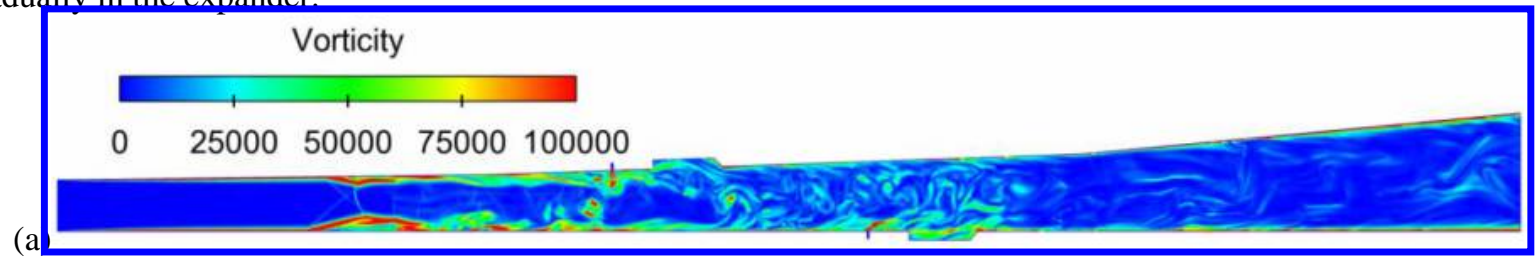

14

American Institute of Aeronautics and Astronautics 


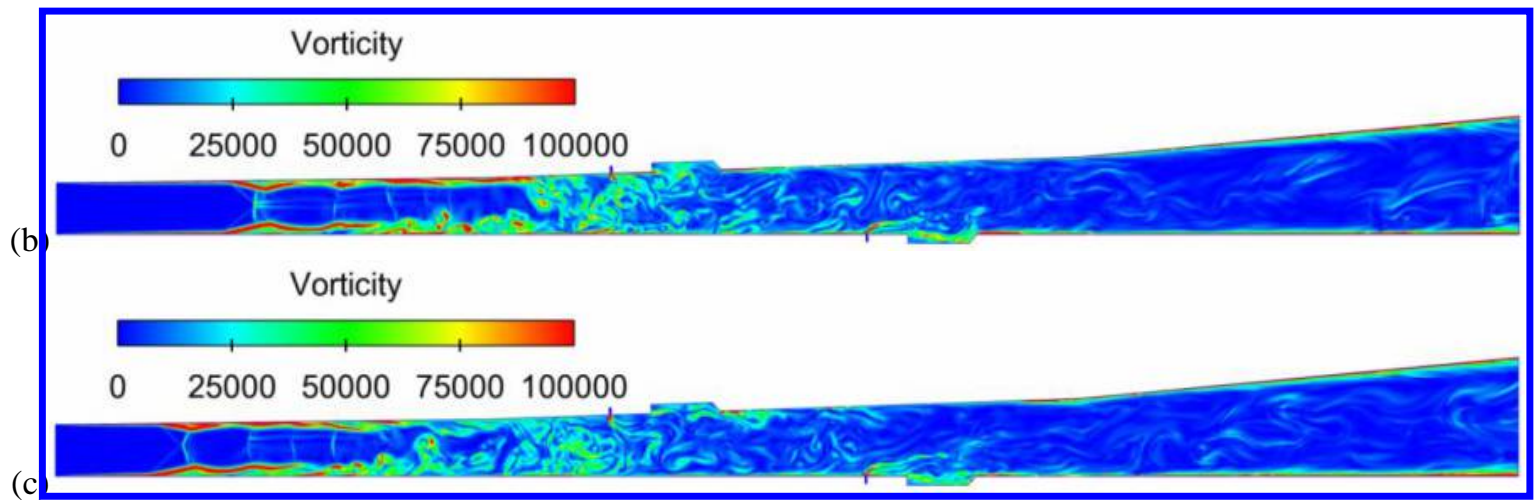

Figure 11. Instantaneous vorticity contours on the streamwise plane through one fuel injector $(\mathrm{Z}=\mathbf{5 7} \mathrm{mm})$ for different fuel equivalence ratios: (a) 0.8 . (b) 1.0 . (c) 1.2

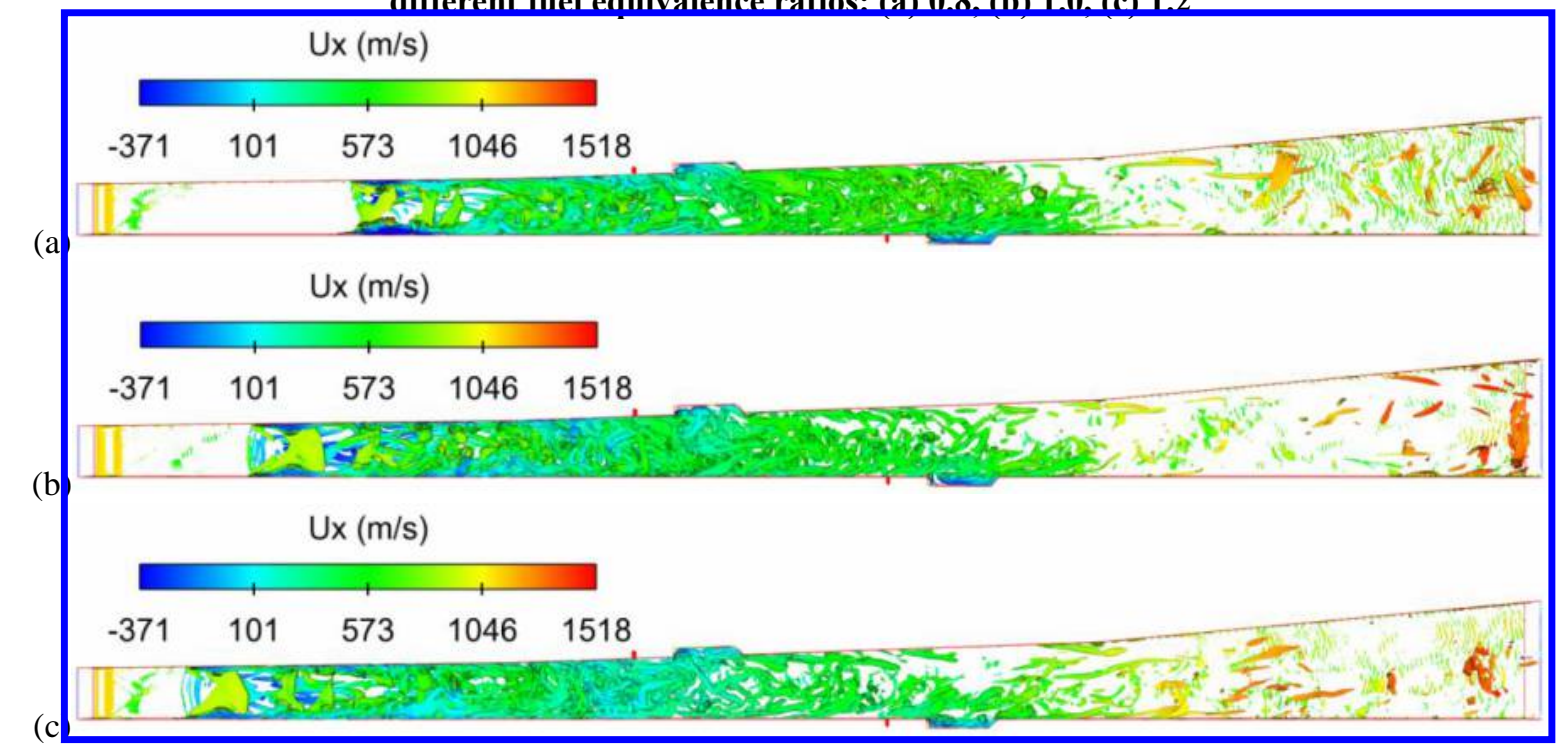

Figure 12. Iso-surfaces of Q-criterion (the second invariant of the velocity gradient tensor, an iso value of $5 \times 10^{7} \mathrm{~s}^{-2}$ used in the plotting) colored by streamwise velocity for different fuel equivalence ratios: (a) 0.8 , (b) 1.0, (c) 1.2

\section{Conclusions}

DES modelings for three reacting cases with different fuel equivalence ratios in a full-scale rectangular scramjet combustor have been presented to validate the modeling framework as well as to investigate the effect of equivalence ratio on the flow and combustion characteristics. The modelings are based on based on a set of skeletal kerosene mechanism, which was reduced in accordance with the specific conditions in the supersonic combustor and to be size affordable for high-fidelity LES based modeling. The modeling results were validated against available experimental measurements and analyzed to reveal the flow and combustion physics which are difficult to be measured, with particular attention given to the flame distribution and holding. The main findings and conclusions are summarized as follows.

1) The predicted and measured time-averaged static pressure on the streamwise direction agree well both in the general trend and the peak value. High pressure mainly distributes around the upstream injector in the combustor, while the pressure rise due to combustion around the downstream fuel injector is unobvious. The pressure rise due to combustion propagates towards the isolator inlet with increasing equivalence ratio, and the high pressure region enlarges as well. The pressure ratio between the peak pressure and the initial pressure increases from $4,4.5$ to 5 as the equivalence ratio increases from $0.8,1.0$ to 1.2. Abrupt pressure rises due to the oblique shocks in train structure can be observed in the isolator.

2) The maximum instantaneous temperature is around $2700 \mathrm{~K}$, and the regions with high temperature (>1966 K) are distributed mainly in the mixing layer following the cavities and attached to the walls. With the increasing of equivalence ratio, the upper high-temperature region thickens gradually and the lower high-temperature region 
expands towards both the cavity and the expander. The main reaction occurs in the mixing layer starting from the leading edge of the cavities, indicating a cavity flame anchoring mode. The predicted heat flux profiles agree well with the measurements in the general trend for the three equivalence ratios, but the peak heat flux is overpredicted for about $20 \%$ in the combustor region.

3) Most of the combustion occurs under subsonic condition and thus the scramjet combustor actually run a ramjet mode with the shock train acts as the first aerodynamic throat. The length of subsonic regions increases with increasing equivalence ratio. Due to the significantly low flow speed (locally $<100 \mathrm{~m} / \mathrm{s}$ ) in the cavities, the flow residence time is on the same order magnitude of the ignition delay of kerosene, implying a quasi-equilibrium reaction can be reached there to provide not only high temperature but also rich radicals for the flame anchoring. For the upstream part, the fuel stream interacts with the reacting layer rooting at the leading edge of cavity at a cross point, form which the flame can propagate upstream to ignite the fuel in the jet wake should the flame speed becomes high enough under certain conditions, e.g. high-enthalpy incoming flow shortens the ignition delay or the fuel stream is simply changed in compositions.

4) With the increasing of equivalence ratio, the vorticity strengthens and broadens due to the increasing in combustion heat release and the distortion of crossflow by transverse jet with increasing penetration height. The vorticity enhancement in the isolator will promote the turbulent mixing in the downstream combustor, which will further increase the combustion efficiency and thereby total heat release. The region with the most intense vorticity generation is in front of the upstream injector, corresponding to the static pressure plateau. The vortexes in the isolator are generally streamwise and in large scales, then break up to small scales and in more random orientation in the combustor. The breakup of large-scale vortexes to small-scale twisted vortexes occurs to the peak pressure location, i.e. around the upstream cavity for $\phi=0.8$ while around the upstream injector for $\phi=1.0$ and 1.2.

\section{Acknowledgments}

The funding support for this work was provided by National Natural Science Foundation of China under contract 91016005 and LHD Youth Innovative Foundation under contract 0120481111. The authors are also grateful to National Supercomputer Center in Tianjin for providing computational resource.

\section{References}

1. Heiser, W. H., and Pratt, D. T. Hypersonic airbreathing propulsion. SW, Washington: American Institute of Aeronautics and Astronautics Inc., 1994.

2. Tishkoff, J. M., J., P. D., Edwards, T., and Neijad, A. S. "Future directions of supersonic combustion research -air forcenasa workshop on supersonic combustion," 35th Aerospace Sciences Meeting and Exhibit, Reno, Nevada, 1997.

3. $\quad$ Fureby, C., Chapuis, M., Fedina, E., and Karl, S. "CFD analysis of the hyshot II scramjet combustor," Proceedings of the Combustion Institute, Vol. 33, No. 2, 2011, pp. 2399-2405.

4. Larsson, J., Vicquelin, R., and Bermejo-Moreno, I. "Large eddy simulations of the hyshot II scramjet," Annual Research Briefs 2011, Center for Turbulence Research, 2011.

5. Cecere, D., Ingenito, A., Bruno, C., Giacomazzi, E., and Donato, F. "Advances in LES of the hyshot II scramjet combustor," Processes and Technologies for a Sustainable Energy, Ischia, 2010.

6. Antonella, I., Claudio, B., and Donato, C. "LES of the hyshot scramjet combustor," 48th AIAA Aerospace Sciences Meeting Including the New Horizons Forum and Aerospace Exposition, Orlando, Florida, 2010, AIAA 2010-758.

7. Johan, L. "Large eddy simulation of the hyshot II scramjet combustor using a supersonic flamelet model," 48th AIAA/ASME/SAE/ASEE Joint Propulsion Conference \& Exhibit, Atlanta, Georgia, 2012, AIAA 20124261.

8. Romagnosi, L., Ingenito, A., Cecere, D., Giacomazzi, E., and Bruno, C. "The role of the baroclinic term in supersonic fuel/air mixing enhancement," 49th AIAA Aerospace Sciences Meeting including the New

Horizons Forum and Aerospace Exposition, Orlando, Florida, 2011, AIAA 2011-401.

9. $\quad$ Cecere, D., Ingenito, A., Giacomazzi, E., Romagnosi, L., and Bruno, C. "Hydrogen/air supersonic combustion for future hypersonic vehicles," International Journal of Hydrogen Energy, Vol. 36, No. 18, 2011, pp. 11969-11984.

10. Chapuis, M., Fedina, E., Fureby, C., Hannemann, K., Karl, S., and Martinez Schramm, J. "A computational study of the hyshot II combustor performance," Proceedings of the Combustion Institute, Vol. 34, No. 2, 2013, pp. 2101-2109. 
11. Cocks, P. A. T. "Large Eddy Simulation of supersonic combustion with application to scramjet engines," PHD degree, University of Cambridge, 2011.

12. Ingenito, A., and runo, C. B. "Mixing and combustion in supersonic reactive flows," 44th AIAA/ASME/SAE/ASEE Joint Propulsion Conference \& Exhibit, Hartford, Connecticut, 2008, AIAA 20084574.

13. Ingenito, A., De Flora, M. G., and Bruno, C. "LES modeling of scramjet combustion," 44th AIAA Aerospace Sciences Meeting and Exhibit, Reno, 2006.

14. David, P., and Graham, C. "Hybrid RANS/LES of a supersonic combustor," 26th AIAA Applied Aerodynamics Conference, Honolulu, Hawaii, 2008, AIAA 2008-6923.

15. Peterson, D. M., Candler, G. V., and Drayna, T. W. "Detached eddy simulation of a generic scramjet inlet and combustor," 47th AIAA Aerospace Sciences Meeting Including The New Horizons Forum and Aerospace Exposition, Orlando, Florida, 2009, AIAA 2009-130.

16. David, P., Erik, T., and Graham, C. "Hybrid Reynolds-averaged and Large-Eddy Simulation of scramjet fuel injection," 17th AIAA International Space Planes and Hypersonic Systems and Technologies Conference, San Francisco, California, 2011, AIAA 2011-2344.

17. Amarnatha, P., and Jack, E. "LES/RANS simulation of a supersonic combustion experiment," 50th AIAA Aerospace Sciences Meeting including the New Horizons Forum and Aerospace Exposition, Nashville, Tennessee, 2012, AIAA 2012-0611.

18. Edwards, J. R., Potturi, A., and Fulton, J. A. "Large-eddy / Reynolds-averaged Navier-Stokes simulations of scramjet combustor flow fields," 48th AIAA/ASME/SAE/ASEE Joint Propulsion Conference \& Exhibit, Atlanta, Georgia, 2012, AIAA 2012-4262.

19. Fulton, J. A., Edwards, J. R., Hassan, H. A., McDaniel, J. C., Goyne, C. P., Rockwell, R. D., Cutler, A. D., Johansen, C. T., and Danehy, P. M. "Large-eddy/Reynolds-averaged Navier-Stokes simulations of reactive flow in dual-mode scramjet combustor," Journal of Propulsion and Power, Vol. 30, No. 3, 2014, pp. 558575.

20. Fulton, J. A., Edwards, J. R., Hassan, H. A., Rockwell, R., Goyne, C., McDaniel, J., Smith, C., Cutler, A., Johansen, C., Danehy, P. M., and Kouchi, T. "Large-eddy / Reynolds-averaged Navier-Stokes simulations of a dual-mode scramjet combustor," 50th AIAA Aerospace Sciences Meeting including the New Horizons Forum and Aerospace Exposition, Nashville, Tennessee, 2012, AIAA 2012-0115.

-21. Fulton, J. A., Edwards, J. R., Hassan, H. A., McDaniel, J. C., Goyne, C. P., Rockwell, R. D., Cutler, A. D., Johansen, C. T., and Danehy, P. M. "Large-eddy/Reynolds-averaged Navier-Stokes simulations of reactive flow in dual-mode scramjet combustor," Journal of Propulsion and Power, Vol. 30, No. 3, 2011, pp. 558575.

22. Tylczak, E. B., Peterson, D. M., and Candler, G. V. "Hybrid RANS/LES simulation of injection and mixing in the cubrc combustion duct," 20th AIAA Computational Fluid Dynamics Conference, Honolulu, Hawaii, 2011, AIAA 2011-3216.

23. Clark, R. J., and Shrestha, S. O. B. "Review of numerical modeling and simulation results pertaining to high-speed combustion in scramjets," 49th AIAA/ASME/SAE/ASEE Joint PropulsionConference, San Jose, California, 2013, AIAA 2013-3724.

24. Fureby, C. "LES for supersonic combustion," 18th AIAA/3AF International Space Planes and Hypersonic Systems and Technologies Conference, Tours, France, 2012, AIAA 2012-5979.

25. Ladeinde, F. "Advanced computational-fluid-dynamics techniques for scramjet combustion simulation," AIAA Journal, Vol. 48, No. 3, 2010, pp. 513-514.

26. Zilberter, I. A., and Edwards, J. R. "Large-Eddy Simulation/Reynolds-averaged Navier-Stokes simulations of high-speed mixing processes," AIAA Journal, Vol. 52, No. 7, 2014, pp. 1486-1501.

27. You, Y., Ludeke, H., and Hannemann, K. "On the flow physics of a low momentum flux ratio jet in a supersonic turbulent crossflow," Europhysics Letters, Vol. 97, No. 2, 2012, p. 24001.

28. Stephanie, J., David, P., and Graham, C. "Hybrid Reynolds-averaged and Large-Eddy Simulation of supersonic fuel injection scaling," 42nd AIAA Fluid Dynamics Conference and Exhibit, New Orleans, Louisiana, 2012, AIAA 2012-3058.

29. Peterson, D. M., and Candler, G. V. "Hybrid Reynolds-averaged and Large-Eddy Simulation of normal injection into a supersonic crossflow," Journal of Propulsion and Power, Vol. 26, No. 3, 2012, pp. 533544.

30. Boles, J. A., Edwards, J. R., and Bauerle, R. A. "Large-eddy/Reynolds-averaged Navier-Stokes simulations of sonic injection into Mach 2 crossflow," AIAA Journal, Vol. 48, No. 7, 2012, pp. 1444-1456. 
-31. Peterson, D. M., and Candler, G. V. "Hybrid Reynolds-averaged and Large-Eddy Simulation of normal injection into a supersonic crossflow," Journal of Propulsion and Power, Vol. 26, No. 3, 2010, pp. 533544.

32. David, P., and Graham, C. "Supersonic combustor fuel injection simulations using a hybrid RANS/LES approach," 48th AIAA Aerospace Sciences Meeting Including the New Horizons Forum and Aerospace Exposition, Orlando, Florida, 2010, AIAA 2010-411.

33. Su-Hee, W., In-Seuck, J., and Jeong-Yeol, C. "DES investigation of the ignition of hydrogen transverse jet into high enthalpy supersonic crossflow," 47th AIAA Aerospace Sciences Meeting including The New Horizons Forum and Aerospace Exposition, Orlando, Florida, 2009, AIAA 2009-1557.

34. John, B., Jack, E., Jung-Il, C., and Robert, B. "Simulations of high-speed internal flows using LES/RANS models," 47th AIAA Aerospace Sciences Meeting including The New Horizons Forum and Aerospace Exposition, Orlando, Florida, 2009, AIAA 2009-1324.

35. Boles, J. A., Edwards, J. R., and Bauerle, R. A. "Large-eddy/Reynolds-averaged Navier-Stokes simulations of sonic injection into Mach 2 crossflow," AIAA Journal, Vol. 48, No. 7, 2009, pp. 1444-1456.

36. John, B., Jack, E., and Robert, B. "Hybrid LES/RANS simulation of transverse sonic injection into a Mach 2 flow," 46th AIAA Aerospace Sciences Meeting and Exhibit, Reno, Nevada, 2008, AIAA 2008-622.

37. Su-Hee, W., In-Seuck, J., and Jeong-Yeol, C. "DES study of transverse jet injection into supersonic cross flows," 44th AIAA Aerospace Sciences Meeting and Exhibit, Reno, Nevada, 2006, AIAA 2006-1227.

38. Kannepalli, C., Arunajatesan, S., and Dash, S. M. "RANS-LES methodology for supersonic transverse jet interactions with approach flow," 40th AIAA, Aerospace Sciences Meeting and these points based on a gradient criteria. However, this Exhibit, Reno, Nevada, 2002, AIAA-2002-1139, pp. 14-17 January.

39. Rana, Z. A., Thornber, B., and Drikakis, D. "Transverse jet injection into a supersonic turbulent crossflow," Physics of Fluids, Vol. 23, No. 4, 2011, p. 046103.

40. David, P., Pramod, S., and Graham, C. "Simulation of injection into a supersonic crossflow using DES with synthetic inflow," 24th AIAA Applied Aerodynamics Conference, San Francisco, California, 2006, AIAA 2006-3326.

41. Watanabe, J., Kouchi, T., Takita, K., and Masuya, G. "Large-Eddy Simulation of jet in supersonic crossflow with different injectant species," AIAA Journal, Vol. 50, No. 12, 2012, pp. 2765-2778.

42 . Kim, S. H., Donde, P., Raman, V., Lin, K.-C., and Carter, C. "Large eddy simulation based studies of reacting and non-reacting transverse jets in supersonic crossflow," 50th AIAA Aerospace Sciences Meeting including the New Horizons Forum and Aerospace Exposition, Nashville, Tennessee, 2012, AIAA 2012482.

43. Watanabe, J., Kouchi, T., Takita, K., and Masuya, G. "Characteristics of hydrogen jets in supersonic crossflow: Large-Eddy Simulation study," Journal of Propulsion and Power, Vol. 29, No. 3, 2011, pp. 661674.

44. Junya, W., Toshinori, K., Kenichi, T., and Goro, M. "Large-eddy simulations of hydrogen and ethylene injections into a supersonic crossflow," 47th AIAA/ASME/SAE/ASEE Joint Propulsion Conference \& Exhibit, San Diego, California, 2011, AIAA 2011-5764.

45. Ferrante, A., Matheou, G., and Dimotakis, P. E. "LES of an inclined sonic jet into a turbulent crossflow at Mach 3.6," Journal of Turbulence, Vol. 12, No. 2, 2011, pp. 1-32.

46. Génin, F., and Menon, S. "Dynamics of sonic jet injection into supersonic crossflow," Journal of Turbulence, Vol. 11, 2010, p. N4.

47. Kawai, S., and Lele, S. K. "Dynamics and mixing of a sonic jet in a supersonic turbulent crossflow," Annual Research Briefs 2009, Center for Turbulence Research, 2009.

48. Kawai, S., and Lele, S. K. "Large-eddy simulation of jet mixing in a supersonic turbulent crossflow," Annual Research Briefs 2008, Center for Turbulence Research, 2008.

49. Kawai, S., and Lele, S. K. "Mechanisms of jet mixing in a supersonic crossflow: A study using large-eddy simulation," Annual Research Briefs 2007, Center for Turbulence Research, 2007.

50. Fiorina, B., and Lele, S. K. "Numerical investigation of a transverse jet in a supersonic crossflow using Large Eddy Simulation," 36th AIAA Fluid Dynamics Conference and Exhibit, San Francisco, California, 2006, AIAA 2006-3712.

51. Kuo-Cheng, L., Michael, R., Campbell, C., Mark, G., and Charbel, R. "Scalability of ethylene gaseous jets for fueling high-speed air-breathing combustors," 47th AIAA Aerospace Sciences Meeting including The New Horizons Forum and Aerospace Exposition, Orlando, Florida, 2009, AIAA 2009-1423. 

ethylene jets in Mach 2 supersonic crossflow," Journal of Propulsion and Power, Vol. 26, No. 3, 2010, pp. 503-513.

53. Hannemann, K., Karl, S., Martinez Schramm, J., and Steelant, J. "Methodology of a combined ground based testing and numerical modelling analysis of supersonic combustion flow paths," Shock Waves, Vol. 20, No. 5, 2010, pp. 353-366.

54. Santiago, J. G., and Dutton, J. C. "Velocity measurements of a jet injected into a supersonic crossflow," Journal of Propulsion and Power, Vol. 13, No. 2, 1997, pp. 264-273.

-55. VanLerberghe, W. M., Santiago, J. G., Dutton, J. C., and Lucht, R. P. "Mixing of a sonic transverse jet injected into a supersonic flow," AIAA Journal, Vol. 38, No. 3, 2000, pp. 470-479.

56. Santiago, J. G. "An experimental study of the velocity field of a transverse jet injected into a supersonic crossflow," PHD degree, University of Illinois at Urbana-Champaign, 1995.

57. Gruber, M. R., Nejad, A. S., Chen, T. H., and Dutton, J. C. "Transverse injection from circular and elliptic nozzles into a supersonic crossflow," Journal of Propulsion and Power, Vol. 16, No. 3, 2000, pp. 449-457.

$>58$. Gruber, M. R., Nejadt, A. S., Chen, T. H., and Dutton, J. C. "Mixing and penetration studies of sonic jets in a Mach 2 freestream," Journal of Propulsion and Power, Vol. 11, No. 2, 1995, pp. 315-323.

$>59$. Gruber, M. R., Nejad, A. S., Chen, T. H., and Dutton, J. C. "Compressibility effects in supersonic transverse injection flowfields," Physics of Fluids, Vol. 9, No. 5, 1997, p. 1448.

60. Gruber, M. R., Nejad, A. S., and Dutton, J. C. "An experimental investigation of transverse injection from circular and elliptical nozzles into a supersonic crossflow," WL-TR-96-2102, Wright Laboratory, 1996.

$>61$. Ben-Yakar, A., Mungal, M. G., and Hanson, R. K. "Time evolution and mixing characteristics of hydrogen and ethylene transverse jets in supersonic crossflows," Physics of Fluids, Vol. 18, No. 2, 2006 , p. 026101.

62. Aso, S., Kawai, M., and Ando, Y. "Experimental study on mixing phenomena in supersonic flows with slotinjection," 29th Aerospace Sciences Meeting, Reno, Nevada, 1991, AIAA-91-0016.

63. Spaid, F. W., and Zukoski, E. E. "A study of the interaction of gaseous jets from transverse slots with supersonic external flows," AIAA Journal, Vol. 6, No. 2, 1968, pp. 205-212.

64. Maddalena, L., Campioli, T. L., and Schetz, J. A. "Experimental and computational investigation of lightgas injectors in a Mach 4.0 crossflow," Journal of Propulsion and Power, Vol. 22, No. 5, 2006, pp. 10271038.

65. Won, S. H., In-Seuck, J., and Choi, J. Y. "DES modeling of supersonic combustion in scramjet combustors," 42nd AIAA/ASME/SAE/ASEE Joint Propulsion Conference \& Exhibit, Sacramento, California, 2006, AIAA 2006-5097.

66. David, P., Pramod, S., and Graham, C. "DES investigation of transverse injection into supersonic crossflow using a hybrid unstructured solver," 44th AIAA Aerospace Sciences Meeting and Exhibit, Reno, Nevada, 2006, AIAA 2006-903.

67. Choi, J.-Y., Yang, V., Ma, F., Won, S.-H., and Jeung, I.-S. "DES combustion modeling of a scramjet combustor," 42nd AIAA/ASME/SAE/ASEE Joint Propulsion Conference \& Exhibit, Sacramento, California, 2006, AIAA 2006-5097.

68. Fulton, J. A., Edwards, J. R., Hassan, H. A., McDaniel, J. C., Goyne, C. P., Rockwell, R. D., Cutler, A. D., Johansen, C. T., and Danehy, P. M. "Large-eddy/Reynolds-averaged Navier-Stokes simulations of reactive flow in dual-mode scramjet combustor," JOURNAL OF PROPULSION AND POWER, Vol. 30, 2014.

69. David, P., Russell, B., and Vincent, W. "Hybrid Reynolds-averaged and Large-Eddy Simulation of mixing in an axisymmetric scramjet," 18th AIAA/3AF International Space Planes and Hypersonic Systems and Technologies Conference, Tours, France, 2012, AIAA 2012-5902.

70. Jack, E., John, B., and Robert, B. "LES/RANS simulation of a supersonic reacting wall jet," 48th AIAA Aerospace Sciences Meeting Including the New Horizons Forum and Aerospace Exposition, Orlando, Florida, 2010, AIAA 2010-370.

71. Ingenito, A., and Bruno, C. "Physics and regimes of supersonic combustion," AIAA Journal, Vol. 48, No. 3, 2010, pp. 515-525.

72. Jung, C., and Suresh, M. "Large-Eddy Simulation of cavity-stabilized supersonic combustion," 45th AIAA/ASME/SAE/ASEE Joint Propulsion Conference \& Exhibit, Denver, Colorado, 2009, AIAA 20095383.

73. Chaitanya, G., Jung, C., Srikant, S., and Suresh, M. "Large Eddy Simulation of supersonic combustion in a cavity-strut flameholder," 49th AIAA Aerospace Sciences Meeting including the New Horizons Forum and Aerospace Exposition, Orlando, Florida, 2011, AIAA 2011-323. 
74. Jung, C., Chaitanya, G., and Suresh, M. "Large-Eddy Simulation of cavity flame-holding in a Mach 2.5 cross flow," 48th AIAA Aerospace Sciences Meeting Including the New Horizons Forum and Aerospace Exposition, Orlando, Florida, 2010, AIAA 2010-414.

-75. Sun, M.-b., Geng, H., Liang, J.-h., and Wang, Z.-g. "Mixing characteristics in a supersonic combustor with gaseous fuel injection upstream of a cavity flameholder," Flow, Turbulence and Combustion, Vol. 82, No. 2, 2008, pp. 271-286.

76. Man, Z., Zhiwei, H., Kai Hong, L., and Guoqiang, H. "LES of kerosene spray combustion with pilot flame in a model dual mode ramjet chamber," 45th AIAA/ASME/SAE/ASEE Joint Propulsion Conference \& Exhibit, Denver, Colorado, 2009, AIAA 2009-5385.

-77. Liu, P., He, G., Hu, Z., and Zhang, M. "Large-eddy simulation of kerosene spray combustion in a model scramjet chamber," Proceedings of the Institution of Mechanical Engineers, Part G: Journal of Aerospace Engineering, Vol. 224, No. 9, 2010, pp. 949-960.

78. Kumaran, K., and Babu, V. "Mixing and combustion characteristics of kerosene in a model supersonic combustor," Journal of Propulsion and Power, Vol. 25, No. 3, 2009, pp. 583-592.

79. Kumaran, K., Behera, P. R., and Babu, V. "Numerical investigation of the supersonic combustion of kerosene in a strut-based combustor," Journal of Propulsion and Power, Vol. 26, No. 5, 2010, pp. 10841091.

-80. Lu, T., and Law, C. K. "Toward accommodating realistic fuel chemistry in large-scale computations," Progress in Energy and Combustion Science, Vol. 35, No. 2, 2009, pp. 192-215.

81. Yu, G., and Fan, X. "Supersonic combustion and hypersonic propulsion," Advances in Mechanics, Vol. 43, No. 5, 2013, pp. 449-471.

82. Hautman, D. J., Dryer, F. L., Schug, K. P., and Glassman, I. "A multiple-step overall kinetic mechanism for the oxidation of hydrocarbons," Combustion Science and Technology, Vol. 25, No. 5-6, 1981, pp. 219-235.

83. Westbrook, C. K., and Dryer, F. L. "Chemical kinetic modeling of hydrocarbon combustion," Progress in Energy and Combustion Science, Vol. 10, No. 1, 1984, pp. 1-57.

84. Franzelli, B., Riber, E., Sanjosé, M., and Poinsot, T. "A two-step chemical scheme for kerosene-air premixed flames," Combustion and Flame, Vol. 157, No. 7, 2010, pp. 1364-1373.

85. Choi, J.-Y. "A quasi global mechanism of kerosene combustion for propulsion applications," 47th AIAA/ASME/SAE/ASEE Joint Propulsion Conference \& Exhibit, San Diego, California, 2011, AIAA 20115853.

-86. Turanyi, T. "Applications of sensitivity analysis to combustion chemistry," Reliability Engineering and System Safety, Vol. 57, 1997, pp. 41-48.

87. Segel, L. A., and Slemrod, M. "The quasi-steady-state assumption: A case study in perturbation," SIAM Review, Vol. 31, No. 3, 1989, pp. 446-477.

88. Bisi, M., Conforto, F., and Desvillettes, L. "Quasi-steady-state approximation for reaction-diffusion equations," Bulletin of the Institute of Mathematics Academia Sinica (New Series), Vol. 2, No. 4, 2007, pp. 823-850.

$>89$.

Rein, M. "The partial-equilibrium approximation in reacting flows," Physics of Fluids A: Fluid Dynamics, Vol. 4, No. 5, 1992, p. 873.

90. Ramshaw, J. D. "Partial chemical equilibrium in fluid dynamics," Physics of Fluids, Vol. 23, No. 4, 1980, p. 675.

-91. Lu, T., and Law, C. K. "A directed relation graph method for mechanism reduction," Proceedings of the Combustion Institute, Vol. 30, No. 1, 2005, pp. 1333-1341.

92. Pepiotdesjardins, P., and Pitsch, H. "An efficient error-propagation-based reduction method for large chemical kinetic mechanisms," Combustion and Flame, Vol. 154, No. 1-2, 2008, pp. 67-81.

-93. Niemeyer, K. E., Sung, C.-J., and Raju, M. P. "Skeletal mechanism generation for surrogate fuels using directed relation graph with error propagation and sensitivity analysis," Combustion and Flame, Vol. 157, No. 9, 2010, pp. 1760-1770.

94. Dagaut, P., Karsenty, F., Dayma, G., Diévart, P., Hadj-Ali, K., Mzé-Ahmed, A., Braun-Unkhoff, M., Herzler, J., Kathrotia, T., Kick, T., Naumann, C., Riedel, U., and Thomas, L. "Experimental and detailed kinetic model for the oxidation of a gas to liquid (GtL) jet fuel," Combustion and Flame, Vol. 161, No. 3, 2014, pp. 835-847.

-95. Dagaut, P., and Cathonnet, M. "The ignition, oxidation, and combustion of kerosene: A review of experimental and kinetic modeling," Progress in Energy and Combustion Science, Vol. 32, No. 1, 2006, pp. 48-92. 
-96. Spalart, P. R. "Detached-eddy simulation," Annual Review of Fluid Mechanics, Vol. 41, No. 1, 2009, pp. 181-202.

97. Spalart, P. R., Jou, W. H., Strelets, M., and Allmaras, S. R. "Comments on the feasibility of LES for wings and a hybrid RANS/LES approach," First AFOSR Conference on DNS/LES, Ruston, Louisiana, 1997.

98. Spalart, P. R., and Allmaras, S. R. "A one-equation turbulence model for aerodynamic flows," 30th Aeropsace Sciences Meeting \& Exhibit, Reno, Nevada, 1992, AIAA-92-0439.

99. Edward, S., Suhee, W., Cho, D. R., and Choi, J. Y. "Hybrid RANS/LES study of base-bleed flows in supersonic mainstream," 15th AIAA International Space Planes and Hypersonic Systems and Technologies Conference, Dayton, Ohio, 2008, AIAA 2008-2588.

100. Shur, M., Spalart, P. R., Strelets, M., and Travin, A. "Detached eddy simulation of an airfoil at high angle of attack," 4th International Symposium on Engineering Turbulence Modeling and Measurements, Corsica, France, 1999.

101. Menter, F. R., Kuntz, M., and Langtry, R. "Ten years of industrial experience with the sst turbulence model," Turbulence, heat and mass transfer, Begell House Inc., 2003, pp. 625-632.

102. Spalart, P. R., Deck, S., Shur, M. L., Squires, K. D., Strelets, M. K., and Travin, A. "A new version of detached-eddy simulation, resistant to ambiguous grid densities," Theoretical and Computational Fluid Dynamics, Vol. 20, 2006, pp. 181-195.

103. Travin, A. K., Shur, M. L., Spalart, P. R., and Strelets, M. K. "Improvement of delayed detached-eddy simulation for LES with wall modelling," European Conference on Computational Fluid Dynamics, TU Delft, The Netherlands, 2006.

-104. Shur, M. L., Spalart, P. R., Strelets, M. K., and Travin, A. K. "A hybrid RANS-LES approach with delayed-DES and wall-modelled LES capabilities," International Journal of Heat and Fluid Flow, Vol. 29, 2008, pp. 1638-1649.

105. Fan, Z., Liu, W., Sun, M., Wang, Z., Zhuang, F., and Luo, W. "Theoretical analysis of flamelet model for supersonic turbulent combustion," Science China Technological Sciences, Vol. 55, No. 1, 2011, pp. 193205.

106. Turns, S. R. An introduction to combustion: Concepts and applications (3rd Ed.). New York: McGraw Hill Education, 2011.

107. Li, X., Zhang, T., Qi, L., and Fan, X. "Characteristic scales and influential factors in supersonic combustion," Journal of Aerospace Power, Vol. 28, No. 7, 2013, pp. 1458-1466.

108. Golovitchev, V. I., and jarnicki, R. "Numerical modeling of high temperature air "flameless" combustion," The 4th International Symposium on High Temperature Air Combustion and Gasification, Rome, Italy, 2001.

109. Golovitchev, V. I., Nordin, N., Jarnicki, R., and Chomiak, J. CEC/SAE Spring Fuels \& Lubricants Meeting \& Exposition, Paris, France, 2000.

110. magnussen, B. F. "Modeling of nox and soot formation by the eddy dissipation concept," International Flame Research Foundation First Topic Oriented Technical Meeting, Amsterdam, The Netherlands, 1989.

111. Magnussen, B. F. "The eddy dissipation concept: A bridge between science and technology," ECCOMAS Thematic Conference on Computational Combustion, Lisbon, Portugal, 2005.

112. Hallaji, M., and Mazaheri, K. "Numerical simulation of turbulent non-premixed combustion in diluted hot coflow using pasr combustion model," 7th Mediterranean Combustion Symposium, Sardinia, Italy, 2011.

113. Magnussen, B. F., and Hjertager, B. H. "On mathematical modeling of turbulent combustion with special emphasis on soot formation and combustion," Proceedings of the Combustion Institute, Vol. 16, 1977, pp. 719 719-729.

114. Edwards, T., and Maurice, L. Q. "Surrogate mixtures to represent complex aviation and rocket fuels," Journal of Propulsion and Power, Vol. 17, No. 2, 2001, pp. 461-466.

115. Fan, X., and Yu, G. "Analysis of thermophysical properties of Daqing RP-3 aviation kerosene," Journal of Propulsion Technology, Vol. 27, No. 2, 2006, pp. 187-192.

116. Huber, M. L. NIST thermophysical properties of hydrocarbon mixtures database (SUPERTRAPP) v3.1: National Institute of Standards and Technology, 2003.

117. Dagaut, P. "On the kinetics of hydrocarbons oxidation from natural gas to kerosene and diesel fuel," Physical Chemistry Chemical Physics, Vol. 4, No. 11, 2002, pp. 2079-2094.

118. Lutz, A. E., Kee, R. J., and Miller, J. A. Senkin: A fortran program for predicting homogeneous gas phase chemical kinetics with sensitivity analysis. Livermore, CA: Sandia National Laboratories, 1988.

119. Pope, S. B. "Computationally efficient implementation of combustion chemistry using in situ adaptive tabulation," Combustion Theory and Modeling, Vol. 1, 1997, pp. 41-63. 
120. Yang, B., and Pope, S. B. "Treating chemistry in combustion with detailed mechanisms - in situ adaptive tabulation in principal directions - premixed combustion," Combustion and Flame, Vol. 112, 1998, pp. 85112.

121. OpenCFD Ltd. Openfoam 2.3.0. http://www.openfoam.org/, 2014.

122. Kurganov, A., and Tadmor, E. "New high-resolution central schemes for nonlinear conservation laws and convection-diffusion equations," Journal of Computational Physics, Vol. 160, No. 1, 2000, pp. 241-282.

123. Greenshields, C. J., Weller, H. G., Gasparini, L., and Reese, J. M. "Implementation of semi-discrete, nonstaggered central schemes in a colocated, polyhedral, finite volume framework, for high-speed viscous flows," International Journal for Numerical Methods in Fluids, Vol. 38, No. 2, 2009, pp. 139-161.

124. Vuorinen, V., Wehrfritz, A., Yu, J., Kaario, O., Larmi, M., and Boersma, B. J. "Large-Eddy Simulation of subsonic jets," Journal of Physics: Conference Series, Vol. 318, No. 3, 2011, p. 032052.

125. Baba-Ahmadi, M. H., and Tabor, G. "Inlet conditions for LES using mapping and feedback control," Computers \& Fluids, Vol. 38, No. 6, 2009, pp. 1299-1311.

126. Vuorinen, V., Yu, J., Tirunagari, S., Kaario, O., Larmi, M., Duwig, C., and Boersma, B. J. "Large-eddy simulation of highly underexpanded transient gas jets," Physics of Fluids, Vol. 25, No. 1, 2013, p. 016101.

127. Vuorinen, V., Wehrfritz, A., Duwig, C., and Boersma, B. J. "Large-eddy simulation on the effect of injection pressure and density on fuel jet mixing in gas engines," Fuel, Vol. 130, 2014, pp. 241-250.

128. Markarian, C. F. "Heat transfer in shock wave - boundary layer interaction regions," NWC TP-4485, Naval Weapons Center, 1968.

129. Cohen, L. S., Coulter, L. J., and Egan Jr., W. J. "Penetration and mixing of multiple gas jets subjected to a cross flow," AIAA Journal, Vol. 9, No. 4, 1971, pp. 718-724.

130. Billig, F. S., Orth, R. C., and Alasky, M. "A unified analysis of gaseous jet penetration," AIAA Journal, Vol. 9, No. 6, 1971, pp. 1048-1057.

131. Cheng, D., Fan, X., and Yang, M. "Quasi-1D compressible flow of hydrocarbon fuel," 48th AIAA/ASME/SAE/ASEE Joint Propulsion Conference \& Exhibit, Atlanta, Georgia, 2012, AIAA 2012-4090.

132. Dubief, Y., and Delcayre, F. "On coherent-vortex identification in turbulence," Journal of Turbulence, Vol. 1, 2000, p. N11. 